\title{
SEISMIC DESIGN CONSIDERATIONS OF THE PROPERTIES OF NEW ZEALAND MANUFACTURED STEEL REINFORCING BARS
}

\author{
T. Andriono' and R. Park2
}

\begin{abstract}
SYNOPSIS
A statistical study is carried out to investigate the probable stress-strain properties of Grade 275 and Grade 380 reinforcing steel manufactured in New Zealand for reinforced concrete construction. The investigation is based on extensive measured data obtained from Pacific Steel Ltd and from University of Canterbury research projects.

The results obtained from this statistical study are used to calculate the 5\% lower-tail normal probability value of the yield strength, which is considered to be more appropriate for use in the strength design of reinforced concrete members than the specified minimum yield strength.

The results obtained from this statistical study are also used to re-evaluate the values of the currently recommended beam flexural overstrength factors used in seismic design in New Zealand, namely 1.25 if Grade 275 steel is used as flexural reinforcement and 1.40 if Grade 380 steel is used as flexural reinforcement. For this purpose, moment-curvature analyses incorporating an appropriate stress-strain model for the steel reinforcement and the Monte Carlo simulation technique are conducted to study the likely increase in the flexural strength above the ideal moment capacity of reinforced concrete members at high curvatures. Improved values for the flexural overstrength factors are recommended.
\end{abstract}

\section{INTRODUCTION}

New Zealand codes $[1,2]$ require that ductile reinforced concrete structures should be the subject of capacity design to ensure that non-ductile failure modes, such as soft-storey column mechanisms or shear failures, do not occur. In the capacity design approach, parts of elements of the primary earthquake load resisting system are detailed for adequate ductility. Sufficient strength is then provided to all other possible mechanisms of failure to ensure that the chosen ductile mode of inelastic deformation can be maintained during severe seismic loading. For ductile reinforced concrete moment resisting frames and structural walls the inelastic behaviour is designed to occur by flexural deformation at ductile plastic hinge regions.

In capacity design it is obviously important to be able to calculate the likely variations in the flexural strength of members, which in turn requires information on the likely variations in the strengths of the materials used.

1. PhD Student, Department of Civil Engineering, University of Canterbury, New Zealand.

2. Professor and Head of Civil Engineering, University of Canterbury, New Zealand.
Generally the actual strengths of the steel and concrete are greater than the specified strengths. Also, previous investigations $[4,5]$ have shown that the increase in steel stress due to strain hardening at strains greater than at yield can cause a significant increase in the flexural strength of members. To avoid adverse consequences of these strength increases, commonly referred to as "overstrength", it is usual in seismic design to calculate the shear forces in beams and beam-column joint cores, and the input moments and axial forces into columns, on the basis of a longitudinal steel stress at the beam plastic hinge regions which is greater than the specified yield strength of the reinforcing steel. The Commentary of the New Zealand concrete design code [3] recommends for beams flexural overstrength factors of 1.25 for Grade 275 longitudinal steel and 1.40 for Grade 380 longitudinal steel. These flexural overstrength values appear to have arisen [5] for Grade 275 steel from a likely steel yield strength which is $15 \%$ greater than the specified yield strength plus a $10 \%$ increase due to strain hardening, and for Grade 380 steel from a likely steel yield strength which is $6 \%$ greater than the specified yield strength plus a $34 \%$ increase due to strain hardening. These currently used flexural overstrength factors are rounded approximate values based on the limited data on New Zealand manufactured reinforcing steel available in the $1970 \mathrm{~s}$. 
This paper presents a re-evaluation of the overstrength factors for concrete members reinforced with New Zealand manufactured steel. First, a statistical study was carried out to investigate the likely variations in the yield strengths and in the other stress-strain properties of reinforcing steel manufactured by Pacific Steel Ltd based on the extensive measured data now available. Then, theoretical moment-curvature analyses were conducted for a range of reinforced concrete sections. The analyses incorporated the Monte Carlo simulation technique to obtain the beam flexural overstrengths taking into account the likely variations in the steel and concrete properties. Flexural overstrength factors for use in capacity design are suggested as a result. The results of this study may be seen reported in more detail elsewhere [6].

\section{STATISTICAL STUDY OF THE STRESS- STRA IN PROPERTIES OF NEW ZEALAND MANUFACTURED REINFORCING STEEL}

\section{I General}

The New Zealand manufactured Grades 275 and 380 steel reinforcing bars for concrete are covered by NZS 3402P:1973 [7]. The New Zealand concrete design code 3101: 1982 requires that only deformed bars shall be used for longitudinal non-prestressed reinforcement. NZS 3101:1982 also requires that Grade 275 plain round bars shall be used for transverse reinforcement, except that Grade 380 plain bars of up to one-half the diameter of the longitudinal bars may be used as transverse reinforcement provided that such plain bars are permanently identified.

In view of these requirements, this study investigated the likely yield strengths and other stress-strain properties of Grades 275 and 380 deformed bars with a range of diameters from $10 \mathrm{~mm}$ to $32 \mathrm{~mm}$ as used for longitudinal reinforcement, and the likely yield strengths of Grade 275 plain round bars of $10 \mathrm{~mm}$ and 12 $\mathrm{mm}$ diameters as usually used for transverse reinforcement.

In the following sections an appropriate model for the stress-strain behaviour of steel bars is presented and then the variation of the basic parameters of that model are discussed and analysed statistically.

\subsection{Stress-strain Behaviour of Reinforcing steel}

A typical measured stress-strain relationship for reinforcing steel obtained from a monotonic tension test is shown in Fig. 1. The curve comprises three major parts, namely an initial linear elastic portion A-B up to the yield point, a yield plateau B-C with little or no increase in stress, and the strainhardening range $C-D$ where stress again increases with strain until the maximum stress is reached. Beyond point $D$ the remaining elongation takes place mainly over a small length of bar, where necking

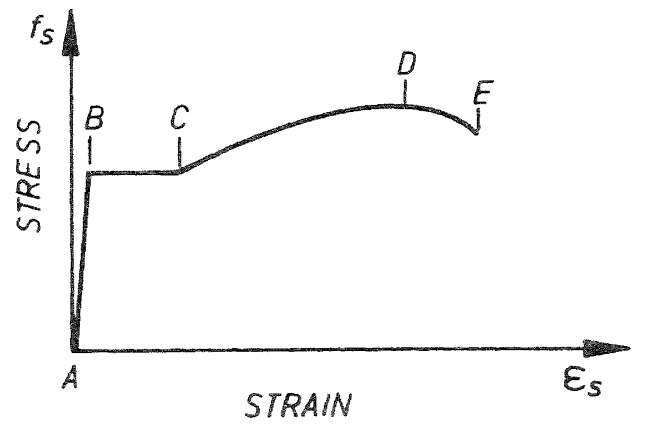

Fig. I Typical Measured Stress-strain Relationship for Steel Bars Used In Reinforced Concrete Members.

of the bar occurs, and the stress falls until fracture occurs at point $E$. The range $D-E$ is less important than the first three parts of the curve.

The slope of the linear elastic region is given by the modulus of elasticity of the steel $E$, which is generally taken as $200,000 \mathrm{MPa}^{\mathrm{s}}[2]$. The stress at the yield point is referred to as the yield strength, $f$, and is a very important parameter of the reinforcing steel. The effects of some factors on the yield strength of reinforcing bars will be discussed in detail later. The length of the yield plateau is generally a function of the strength of the steel. High-strength high-carbon steels usually have a much shorter yield plateau, and also a smaller total elongation before fracture, compared to low-strength low-carbon steels.

To ensure that the structure can perform in a ductile manner during severe seismic loading, it is necessary for the steel to be able to undergo large plastic strains before fracture occurs.

Generally the stress-strain curves for steel found from monotonic tension tests can be assumed to also represent the stress-strain relationship for steel in compression $[4,5]$, although some differences have been observed to exist [8].

A reinforced concrete member will be loaded repeatedly during its life, leading to repeated loading and unloading of the reinforcing bars. Typical stress-strain behaviour for repeated loading of the same sign is illustrated in Fig. 2. If the steel stress is released before failure, recovery occurs along a stress-strain path parallel to the initial elastic branch. If loaded again, the same stress-strain path will be followed up to the original curve, with perhaps a small hystresis and/ or strain-hardening effect. However, generally the monotonic stress-strain curve is then followed as if unloading had not occurred. Hence repetitions of loading of the same sign can be idealised by sets of lines parallel to the original elastic branch, and the monotonic stress-strain relationship gives a good idealisation for the envelope curve of the repeated loading case $[4,5]$. 


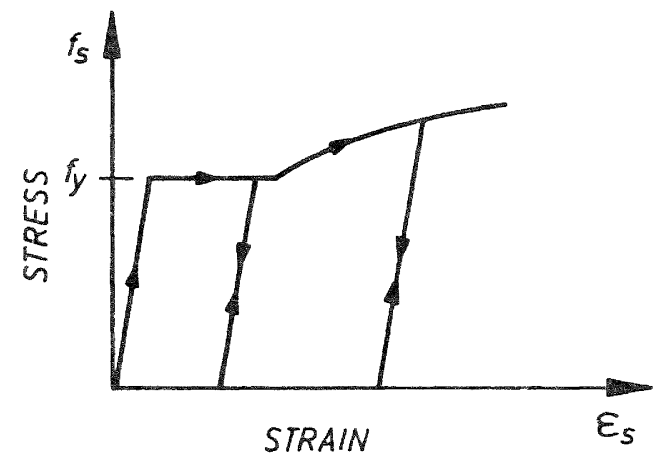

Fig. 2 Typical Measured Stress-Strain Relationship for Steel with Repeated Loading of the Same Sign.

During severe earthquake shaking, structures undergo cyclic (reversed) loading which may cause steel stresses well into the inelastic range. During cyclic loading the stress-strain relationship for reinforcing steel becomes quite different from that associated with repeated loading of the same sign. As shown in Fig. 3, after the first yield excursion the curve becomes non-linear at a stress much lower than the initial yield strength, due to the Bauschinger effect. This stress-strain behaviour is strongly influenced by

previous strain history; time and temperature also have an effect $[4,5,8,9]$.

Those previous investigations have also shown that the monotonic stress-strain curve, with the origin at the initial position, will approximately describe the envelope curve for cyclic loading. providing that the loading occurs mainly in either the tensile strain region or the compressive strain region (see Fig. 3a). For more symmetrical tension-compression strain cycles, the envelope curve for cyclic loading rises above the monotonic stress-strain curve with origin at the original position (see Fig. $3 b$ ).

In beams where the neutral axis is normally not deep in the section, the compression strains reached by the reinforcing steel will generally be much smaller than the tensile strains, which means that the stress-strain hysteresis loops will remain primarily in the fensile strain range. Therefore, for beams the monotonic stress-strain curve for the steel will generally give a good indication of the envelope curve for cyclic stress-strain behaviour for the steel.

\subsection{Monotonic Stress-Strain Model for Reinforcing Steel}

In this study the monotonic stressstrain curve was used to approximate the envelope of the cyclic stress-strain behaviour of reinforcing steel in beams subjected to earthquake loading. The justification of this assumption is as discussed in the previous section.

Various idealisations for the monotonic stress-strain curve have been proposed. For example, both ACI 318-83 [10] and NZS $3101: 1982$ [2] assume an elastic perfectly

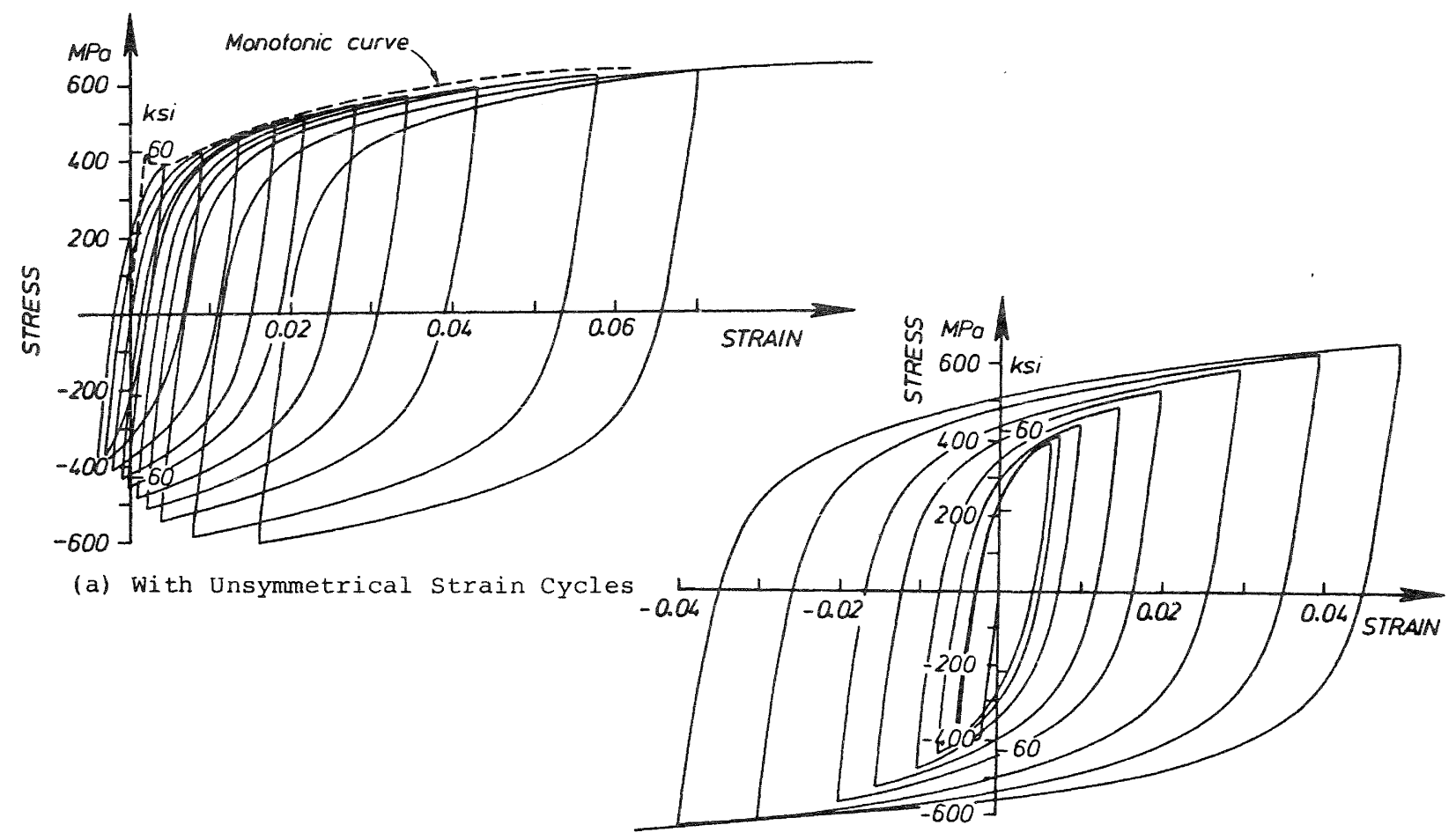

(b) With Symmetrical Strain Cycles

Fig. 3 Typical Measured Stress-Strain Relationships for Steel With Cyclic (Reversed) Loading. 
plastic stress-strain relationship for reinforcing steel which ignores the strength increase due to strain hardening. This simplification will result in a lower bound estimate of the flexural strength of reinforced concrete members, since during severe earthquake loading the actual flexural strength will be increased significantly by strain hardening of the reinforcing steel at strains far beyond its yield point.

Many previous investigators have proposed idealisations for the monotonic stress-strain relationship of reinforcing steel including the strain hardening branch. An idealisation proposed by Mander et al [8], which has been shown to give excellent agreement with a wide range of stress-strain curves in tension and compression for New Zealand manufactured reinforcing steel, was adopted in this study. The idealisaticir is shown in Fig. 4 and is defined by six basic parameters, namely the yield strength, $\mathrm{f}_{y}$; the

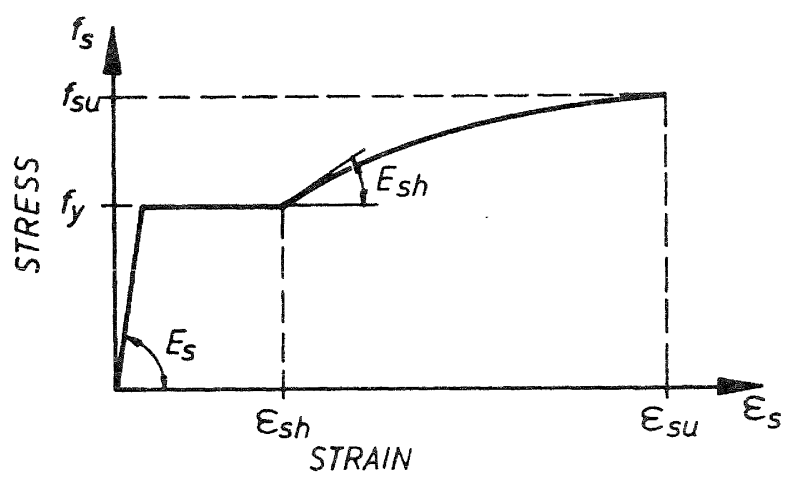

Fig. 4 Monotonic Stress-Strain Curve for Steel and the Six Basic parameters.

ultimate strength, f ; the strain at which strain hardening commences, $E$; the ultimate strain, $\varepsilon_{\text {u }}$; the modulus of elasticity, E; andu' the modulus of strainhardening, $E S^{\circ}$. The regions of the curve are expressed piecewise as follows:

(a) Elastic Region $\left(0 \leqq \varepsilon_{S} \leqq \varepsilon_{y}\right)$

$$
f_{s}=E_{t} \varepsilon_{s}
$$

where the tangent modulus $E_{t}=E_{S}$, and the yield strain $\varepsilon_{y}=\mathrm{f}_{\mathrm{y}} / \mathrm{E}_{\mathrm{s}}$.

(b) Yield plateau $\quad\left(\varepsilon_{y} \leqq \varepsilon_{S} \leqq \varepsilon_{s h}\right)$

$$
\mathrm{f}_{\mathrm{s}}=\mathrm{f}_{\mathrm{y}}
$$

where the tangent modulus $E_{t}$ in this case is equal to 0 .

(c) Strain-Hardening Region ( $\left.\varepsilon_{\text {sh }} \leqq \varepsilon_{s} \leqq \varepsilon_{\text {su }}\right)$

The definition of ultimate strain adopted here is the strain at which ultimate or maximum stress, $f$ occurs, rather than the fracture strain which occurs at a lower stress. Mander et al [8] found that the strain hardening modulus, Esh' was the only parameter necessary to definh' the strain hardening curve, besides the coordinates at each end of the curve ( $\varepsilon_{\text {sh }} f_{y}$ ) and ( $E_{\text {su }} f_{\text {su }}$ ). was:

$$
\left[\frac{f_{s u}-f_{s}}{f_{s u}-f_{y}}\right]=\left[\frac{\varepsilon_{s u}-\varepsilon_{s}}{\varepsilon_{s u}-\varepsilon_{s h}}\right]^{p}
$$

Thus in terms of strain the stress is:

$$
f_{s}=f_{s u}+\left(f_{y}-f_{s u}\right)\left[\frac{\varepsilon_{s u}-\varepsilon_{s}}{\varepsilon_{s u}-\varepsilon_{s h}}\right]^{p}
$$

where $p$ is the strain hardening power and can be determined by differentiating Eq. 4 to give the tangent modulus:

$$
E_{t}=\frac{d f_{s}}{d \varepsilon_{s}}=p\left[\frac{E_{s u}-f_{y}}{\varepsilon_{s u}-\varepsilon_{s h}}\right]\left[\frac{\varepsilon_{s u}-\varepsilon_{s}}{\varepsilon_{s u}-\varepsilon_{s h}}\right]^{p-1}
$$
Since $E_{t}=E_{\text {sh }}$ when $\varepsilon_{s}=\varepsilon_{\text {sh' }}$ therefore
from Eq.

$$
E_{s h}=p\left[\frac{f_{s u}-f_{y}}{\varepsilon_{s u}-\varepsilon_{s h}}\right]
$$

or

$$
p=E_{\text {sh }}\left[\frac{\varepsilon_{\text {su }}-\varepsilon_{\text {sh }}}{E_{\text {su }}-f_{y}}\right]
$$

Mander et al [8] found that the strain hardening branch was predicted very accurately by Eqs. 4 and 6 .

The stress-strain model given by Eqs. 1,2, 4 and 6 was used for the momentcurvature analyses conducted in this study to evaluate the flexurai overstrength of a range of reinforced concrete sections.

Statistical studies of the six basic

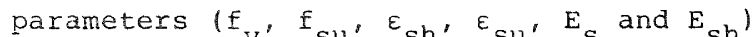
of the stress 'straln model ấe discussed̆ in the following sections.

\subsection{Source and Size of Samples}

A large data base of information on the yield strength, $f$, and the ultimate strength, f , is avallable from Pacific Steel Ltd of Auckland, who manufacture all the reinforcing steel produced in New Zealand. Since NZS 3402P:1973 [7] does not require the producer to provide a full stress-strain curve of the reinforcing steel, data on the other four basic parameters $\left(\varepsilon_{s h}, \varepsilon_{s u} E_{\text {h }}\right.$ and $\left.E_{S}\right)$ from pacific steel std is not exteñsive.

In this study data from Pacific steel Ltd for $f$ and $f$ covering approximately the last ${ }_{\text {ive years of reinforcing bar }}$ manufacture, was used. That data was supplemented by additional data for $f$, $f^{\prime} E_{s h}, E_{s u} E_{s h}$ and $E_{s}$ obtained dufing resunforh'ced cóncrête reseărch projects at the University of Canterbury during approximately the last ten years. 
The size of the sample (that is, the number of samples tested) and the source for each of the six basic parameters for deformed bars used for longitudinal reinforcement are listed in Tables 1 and 2 . For Grade 275 plain round bars of 10 and 12 rum diameter, used as transverse reinforcement, 352 sample results for $f_{y}$
provided by Pacific Steel Ltd were analysed.

\subsection{Variations in the Properties of Longitudinal Reinforcing steel}

The variations of the six basic parameters for each grade of deformed bar reinforcement were investigated. The results of the statistical study are presented below.

\subsubsection{Yield Strength, $\mathrm{f}_{y}$}

The variation in steel yield strength depends on several factors. Mirza and MacGregor [11] have listed the following five causes of variation:

(1) The strength of material itself.

(2) The area of cross section of the bar.

(3) The bar diameter.

(4) The strain at which yield is defined.

(5) The rate of loading.

The above causes of variation are discussed in more detail below.

\section{(1) Variation in the strength of material}

Reinforcing steels, even if produced by the same manufacturer, have small variations in rolling and/or chemical processing from

TABLE 1: Samples Size and Source of Each Parameter for Grade 275 Deformed Bar Reinforcing Steel

\begin{tabular}{|c|c|c|c|c|c|c|c|c|c|c|c|c|c|c|c|c|c|c|c|}
\hline \multirow{3}{*}{ Parameters } & \multicolumn{16}{|c|}{ Diameter of Bars (mm) } & \multirow{2}{*}{\multicolumn{3}{|c|}{$\begin{array}{l}\text { Total of } \\
\text { Samples }\end{array}$}} \\
\hline & \multirow{2}{*}{$\frac{10}{\text { PS UC }}$} & \multicolumn{2}{|l|}{12} & \multicolumn{2}{|c|}{16} & \multicolumn{2}{|c|}{20} & \multicolumn{2}{|c|}{24} & \multicolumn{2}{|c|}{28} & \multicolumn{2}{|c|}{32} & \multirow{2}{*}{$\frac{\# 6}{U C}$} & \multirow{2}{*}{\multicolumn{2}{|c|}{$\begin{array}{l}\# 7 \quad \# 9 \\
U C \quad U C\end{array}$}} & & & \\
\hline & & PS $\quad$ & & PS $\quad$ & & PS & $\mathrm{UC}$ & PS & $\mathrm{UC}$ & PS & $\mathrm{UC}$ & PS & $\mathrm{UC}$ & & & & PS & UC & Sum \\
\hline$f_{y}$ & $54-$ & 200 & - & 4341 & & 306 & 8 & 264 & 7 & 108 & 1 & 152 & - & 1 & - & - & 1518 & 31 & 1549 \\
\hline $\mathrm{f}_{\text {su }}$ & $54-$ & 200 & - & 4341 & 13 & 306 & 7 & 264 & 7 & 108 & 1 & 152 & - & 1 & - & - & 1518 & 29 & 1547 \\
\hline$\varepsilon_{\text {sh }}$ & $-\quad-$ & - & - & -1 & & - & 8 & - & 6 & - & 1 & - & - & 1 & - & - & - & 28 & 28 \\
\hline$\varepsilon_{\text {su }}$ & - & - & - & - & & - & 1 & - & 1 & - & 1 & - & - & - & - & - & - & 8 & 8 \\
\hline $\mathrm{E}_{\mathrm{s}}$ & - & - & - & - & & - & 8 & - & 6 & - & 1 & - & - & 1 & - & - & - & 28 & 28 \\
\hline$E_{\text {sh }}$ & - & - & - & - & 12 & - & 8 & - & 6 & - & 1 & - & - & 1 & - & - & - & 28 & 28 \\
\hline
\end{tabular}

Notes: $\quad$ PS $=$ Pacific Steel Ltả

$\mathrm{UC}=$ University of Canterbury

\#6 $=3 / 4$ in; \#7 $=7 / 8$ in; \#9=9/8 in $(1$ in $=25.4 \mathrm{~mm})$

TABLE 2: Samples Size and Source of Each Parameter for Grade 380 Deformed Bar Reinforcing Steel

\begin{tabular}{|c|c|c|c|c|c|c|c|c|c|c|c|c|c|c|c|c|c|c|c|}
\hline \multirow{3}{*}{ Parameters } & \multicolumn{16}{|c|}{ Diameter of Bars (mm) } & \multirow{2}{*}{\multicolumn{3}{|c|}{$\begin{array}{l}\text { Total of } \\
\text { Samples }\end{array}$}} \\
\hline & \multirow{2}{*}{$\frac{10}{\text { PS UC }}$} & \multicolumn{2}{|c|}{12} & \multicolumn{2}{|c|}{16} & \multicolumn{2}{|c|}{20} & \multicolumn{2}{|c|}{24} & \multicolumn{2}{|c|}{28} & \multicolumn{2}{|c|}{32} & \multirow{2}{*}{$\frac{\# 6}{\text { UC }}$} & \multicolumn{2}{|c|}{$\# 7 \quad \# 9$} & & & \\
\hline & & PS & $\mathrm{UC}$ & PS & UC & PS & UC & PS & UC & PS & UC & PS & $\mathrm{UC}$ & & US & $\mathrm{UC}$ & PS & UC & Sum \\
\hline $\mathrm{f}_{y}$ & $14-$ & 30 & - & 60 & 11 & 80 & 7 & 84 & 5 & 36 & - & 60 & - & - & 1 & 1 & 364 & 25 & 389 \\
\hline$\hat{f}_{\text {su }}$ & $14-$ & 30 & - & 60 & 10 & 80 & 7 & 84 & 5 & 36 & - & 60 & - & - & 1 & 1 & 364 & 24 & 388 \\
\hline$\varepsilon_{\text {sh }}$ & $-\quad-$ & - & - & - & 8 & - & 4 & - & 4 & - & - & - & - & - & 1 & 1 & - & 18 & 18 \\
\hline$\varepsilon_{\mathrm{su}}$ & $-\quad-$ & - & - & - & 3 & - & - & - & - & - & - & - & - & - & - & 1 & - & 4 & 4 \\
\hline$E_{S}$ & $-\quad-$ & - & - & - & 7 & - & 4 & - & 4 & - & - & - & - & - & 1 & 1 & - & 17 & 17 \\
\hline$E_{s h}$ & - & - & - & - & 7 & - & 4 & - & 4 & - & - & - & - & - & 1 & 1 & - & 17 & 17 \\
\hline
\end{tabular}

Notes: $\quad P S=$ Pacific Steel Ltd

UC = University of Canterbury

\#6 $=3 / 4$ in; \#7 $=7 / 8$ in; \#9=9/8 in (1 in $=25.4 \mathrm{~mm})$ 
cast to cast. For this reason, a range of values for the measured yield strength should be expected. It is of interest to note that NZS 3402:P 1973 [7] specifies a minimum yield strength, above which all measured yield strengths must fall, but it does not specify a maximum yield strength which should not be exceeded.

Table 3 shows the results of a statistical anlysis of the variation of the yield strength $f$ which has occurred for New Zealand manulactured reinforcing steel. The columns headed "individual value" give results for all samples listed in Tables I and 2, namely 1549 samples of Grade 275 steel and 389 samples of Grade 380 steel. The columns headed "average value" give results for only the average value for the samples provided by Pacific steel Ltd listed in Tables 1 and 2, namely 759 samples for Grade 275 steel and 182 samples for Grade 380 steel. It should be noted that the data from Pacific steel Ltd is in the form of two values from each cast and those two values are represented by a single average value in the "average value" analyses.

The differences between the mean yield strength, $F$, for the "individual value" and the "ayerage value" in Table 3 are not great. Also, the two values of yield strength taken from each cast of steel typically do not differ much from each other. Hence the analyses which follow are based on the "average value" from pacific steel Ltd.
The distributions of the measured yield strengths for Grades 275 and 380 steel, based on the "average value" samples, are shown in Figs. 5 and 6. respectively. The first step in analysing this data was to determine a suitable model for the distribution of yield strength. It was assumed that the distributions of these samples shown in Figs. 5 and 6 follow the theoretical standard normal distribution. Then this assumption was checked using Gaussian probability paper, which is constructed on the basis of the standard normal distribution, as demonstrated in Fig. 7. In this check the corresponding values of the variable $f$ are plotted against the cumulative probabilities $i /(n+1)$, where $i$ is the number of samples for the corresponding variate $f_{y}$ and $n$ is the total number of samples. $Y$ The linearity, or lack of linearity, of these sets of sample data compared with the straight line of the construction can be used as a preliminary basis for accepting or rejecting the assumed distribution as the appropriate distribution model. Further details concerning the technique of using probability paper are given elsewhere $[12$ 13].

Figs. 8 and 9 show the usage of the probability paper for the "average value" samples of the yield strengths of Grades 275 and 380 steel, respectively. Fig. 8 reveals that the assumption of a normal distribution correlates very well for the samples of Grade 275 steel. Fig. 9 reveals that the assumption of a normal distribution

TABLE 3 : Statistical Data for Yield Strength of Crades 275 and 380 Deformed Bar Reinforcing Steel

\begin{tabular}{|c|c|c|c|c|}
\hline \multirow[t]{2}{*}{ Description } & \multicolumn{2}{|c|}{ Grade 275 steel } & \multicolumn{2}{|c|}{ Grade 380 Steel } \\
\hline & $\begin{array}{l}\text { Individual } \\
\text { Value }\end{array}$ & $\begin{array}{l}\text { Average } \\
\text { Value }\end{array}$ & $\begin{array}{l}\text { Individual } \\
\text { Value }\end{array}$ & $\begin{array}{l}\text { Average } \\
\text { Value }\end{array}$ \\
\hline Total number of samples & 1549 & 759 & 389 & 182 \\
\hline Mean, $\mathrm{f}_{\mathrm{y}}(\mathrm{MPa})$ & 320.8 & 321.3 & 456.0 & 457.8 \\
\hline Standard Deviation (MPa) & 16.1 & 15.5 & 27.6 & 26.3 \\
\hline Coefficient of Variation ( $(\%)$ & 5.02 & 4.82 & 6.05 & 5.74 \\
\hline Maximum Value of data (MPa) & 389.0 & 364.5 & 577.0 & 573.0 \\
\hline Minimum Value of data (MPa) & 260.0 & 277.0 & 360.0 & 395.5 \\
\hline Kolmogorov-Smirnov (KS) Test & & & & \\
\hline (a) Max. (absolute) Difference $D_{\max }$ & 0.0388 & 0.0272 & 0.0630 & 0.0695 \\
\hline $\begin{array}{l}\text { (b) Critical Difference at significance } \\
\text { level } \alpha=1 \% \\
\alpha=5 \% \\
\alpha=10 \%\end{array}$ & $\begin{array}{l}0.0414 \\
0.0346 \\
0.0310\end{array}$ & $\begin{array}{l}0.0592 \\
0.0494 \\
0.0443\end{array}$ & $\begin{array}{l}0.0826 \\
0.0689 \\
0.0619\end{array}$ & $\begin{array}{l}0.1208 \\
0.1008 \\
0.0904\end{array}$ \\
\hline
\end{tabular}

Notes:

* All existing samples are considered as individuals.

** Only average values of each cast from Pacific steel Itd are considered. 


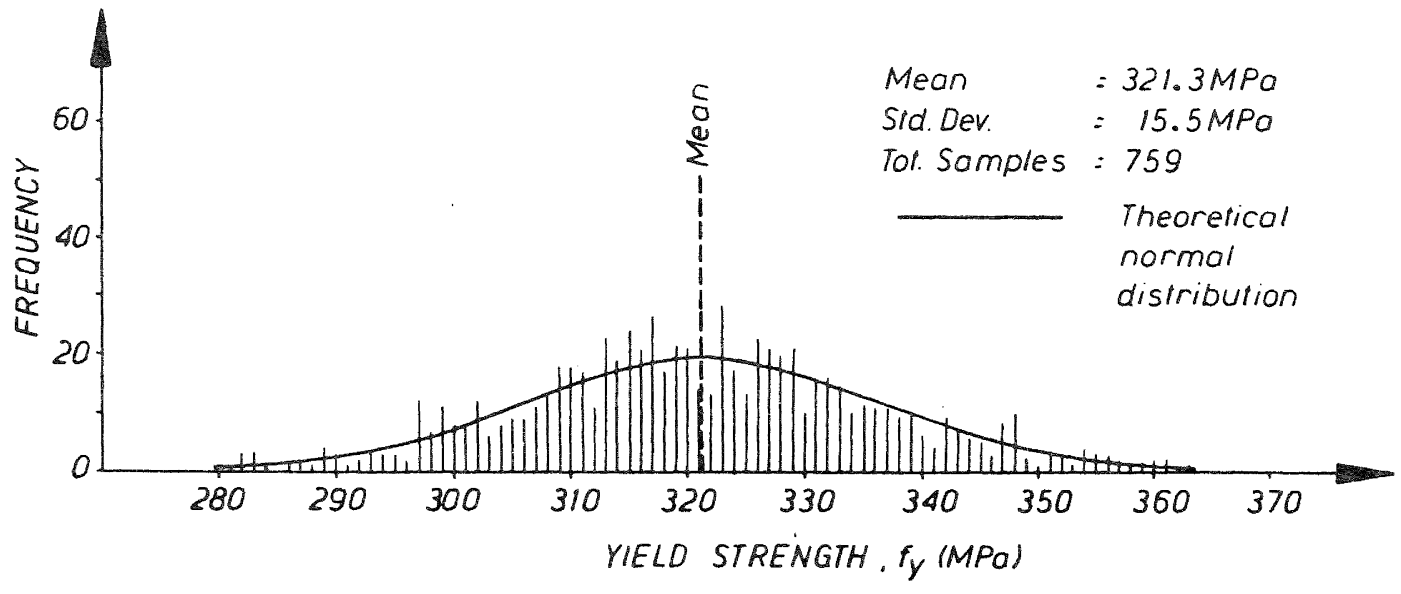

Fig. 5 Histograms of Yield Strengths for Grade 275 Deformed Bar Reinforcing Steel Based on "Average Value" Samples.

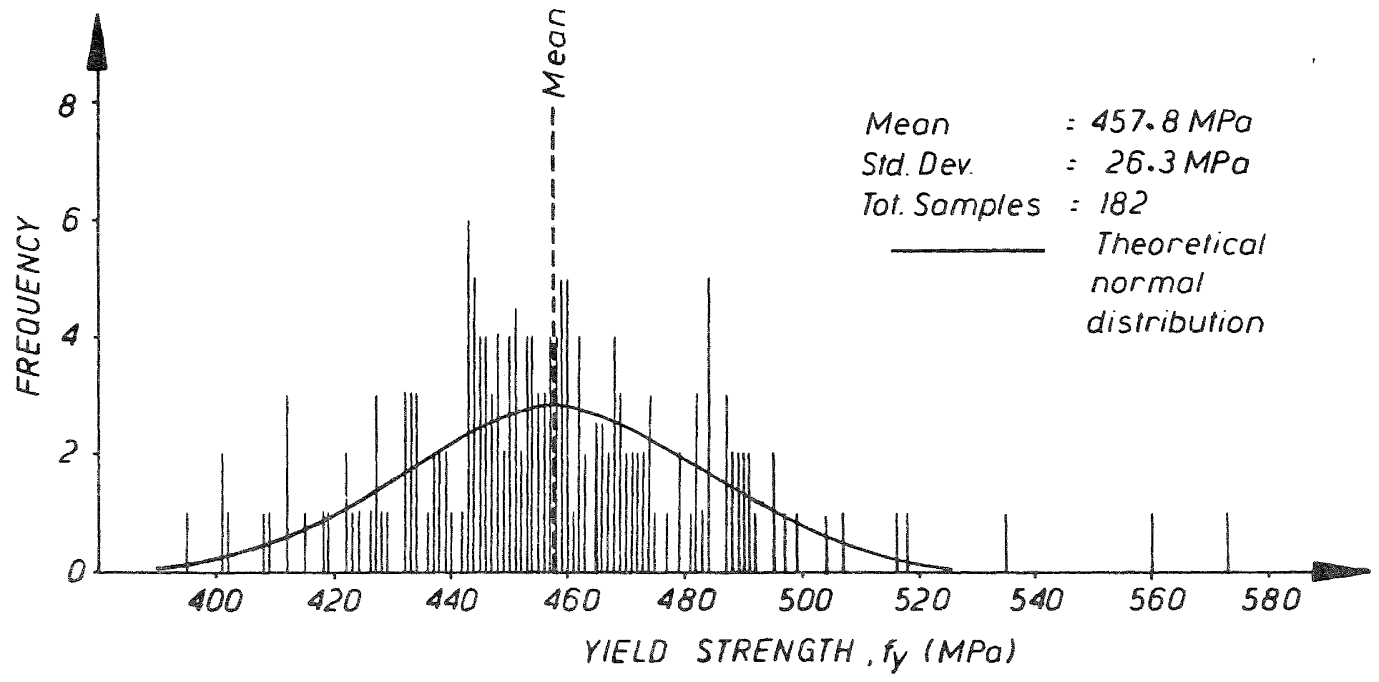

Fig. 6 Histograms of Yield Strengths for Grade 380 Deformed Bar Reinforcing Steel Based on "Average Value" Samples. 


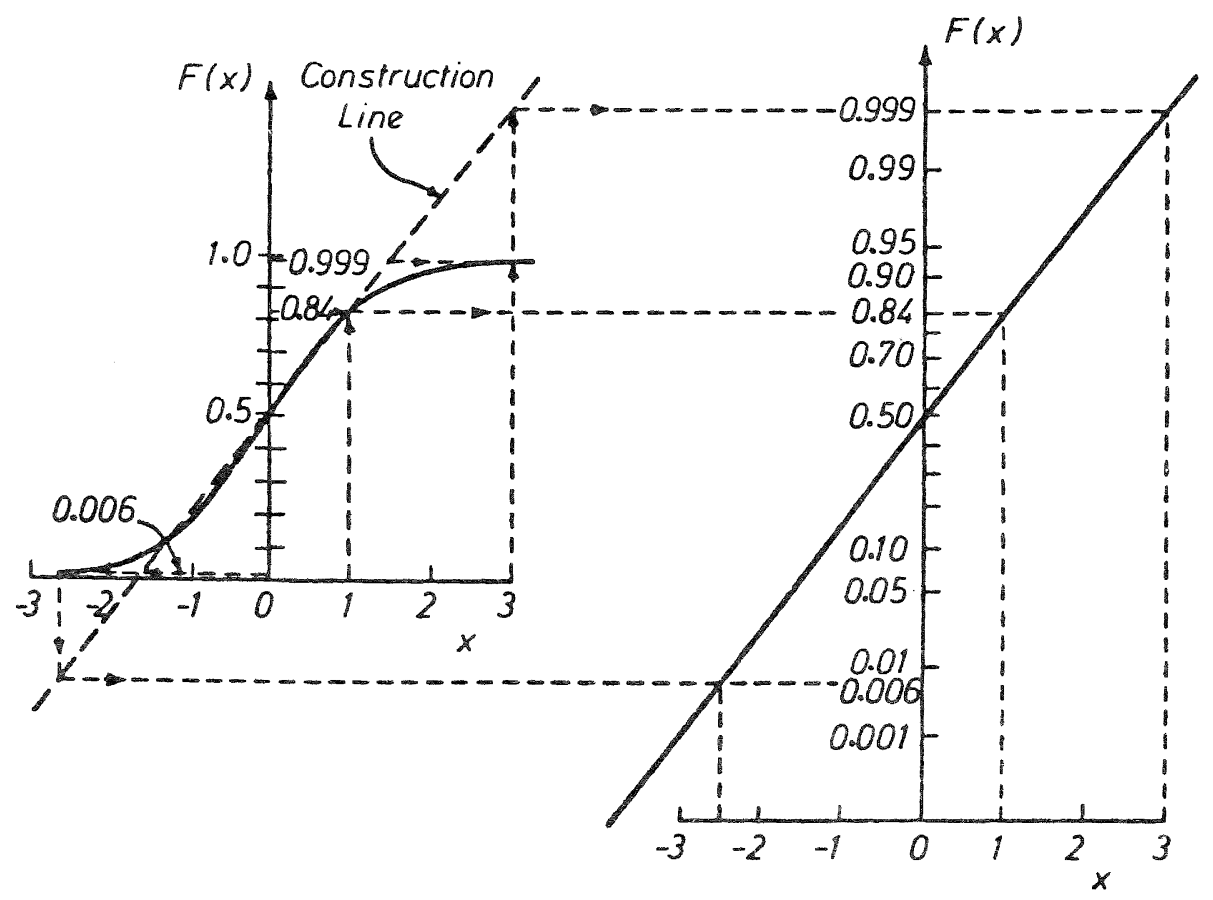

$\begin{array}{ll}\text { (a) Linear Scale } & \text { (b) Probability Paper }\end{array}$ Fig. 7 Construction of Normal Probability Paper.

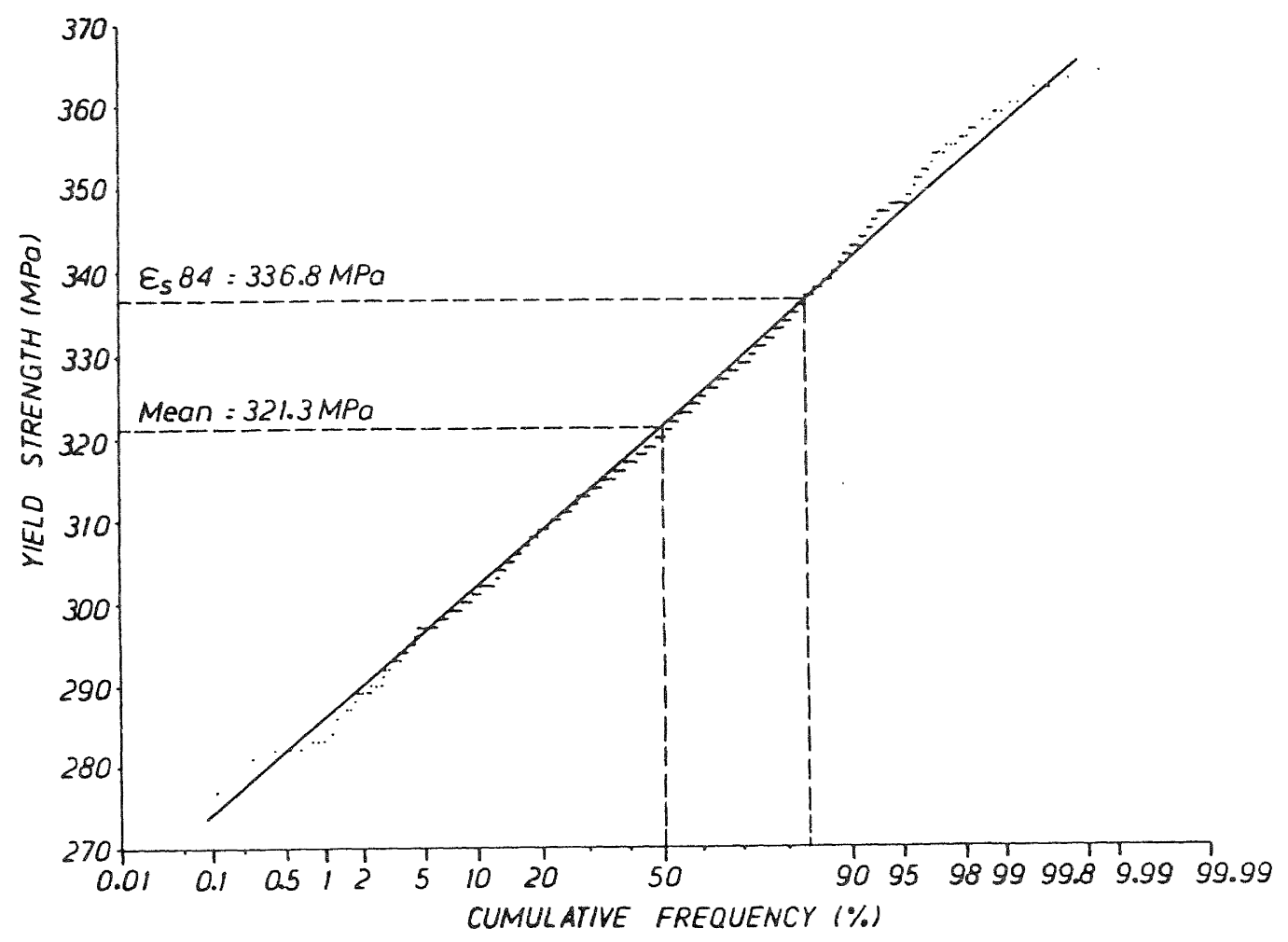

Fig. 8 Cumulative Frequency of the Yield Strengths of Grade 275 Deformed Bar Reinforcing Steel on Normal Probability Paper Based on "Average Value" Samples. 


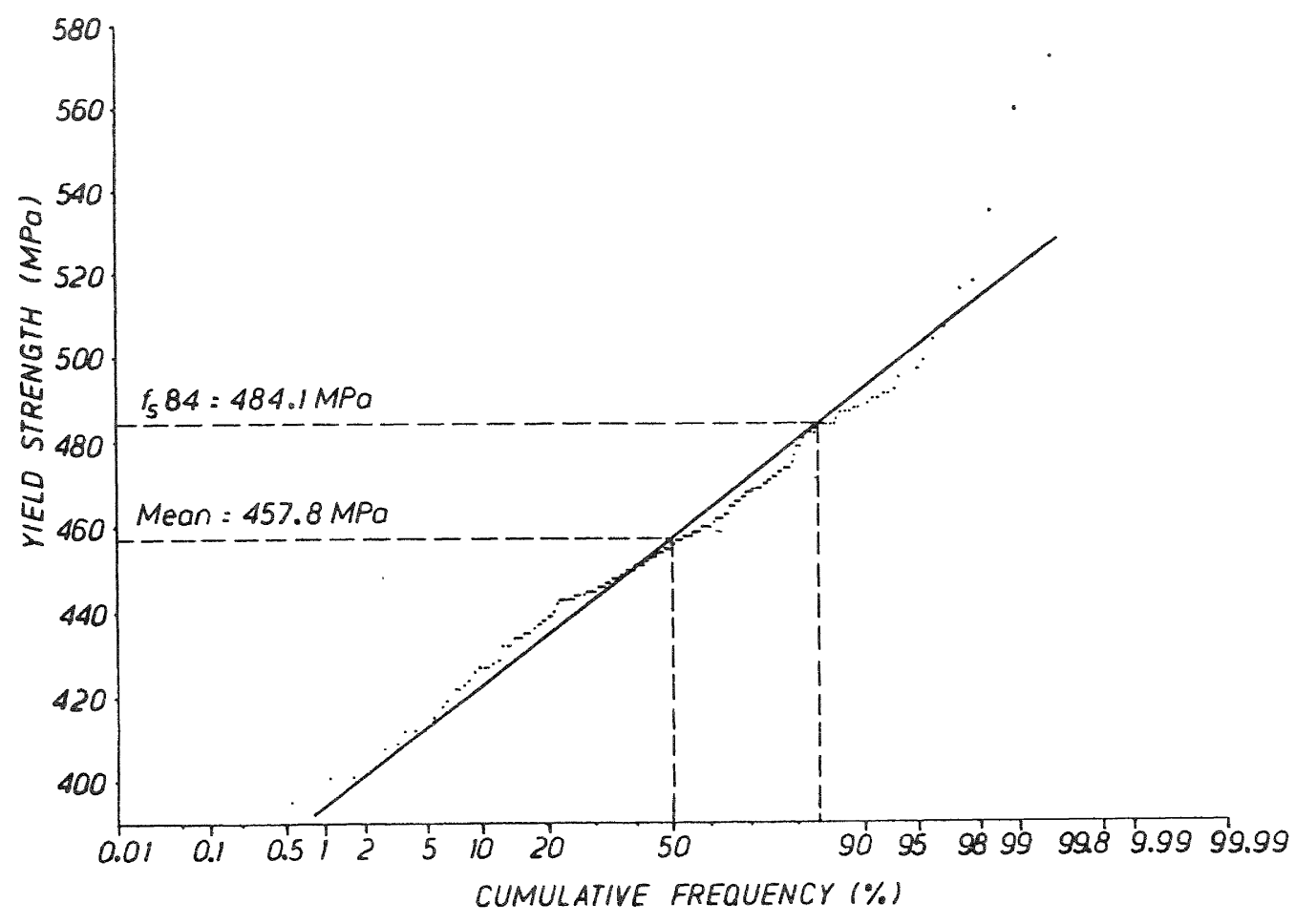

Fig. 9 Cumulative Frequency of the Yield Strengths of Grade 380 Deformed Bar Reinforcing Steel on Normal Probability Paper Based on "Average Value" Samples.

correlates less well for Grade 380 steel, particularly beyond the $98 \%$ probability, since, as shown in Fig. 6 , there are three samples (out of 182) which have extremely high values.

The Kolmogorov-Smirnov (KS) test was also conducted to check the goodness-offit for the distribution of data $[12,13]$. The basic procedure of the KS test involves the comparison between the cumulative frequency of the existing data, $S(x)$, and the assumed theoretical distribution, $F(x)$. The difference between $S_{n}(x)$ and $F(x)$ is

$$
D_{n}=\left|F(x)-s_{n}(x)\right|
$$

where $D$ is a random variable whose distribution depends on number of samples $n$. The maximum value of $D_{n}$ is $D_{\text {max }}$, obtained as illustrated in Fig. ${ }^{n} 10$.

$D_{\text {ax }}$ is then compared with a critical value valuxe $D_{n}^{\alpha}$ for a certain significance level, for example 1\%, $5 \%$ or $10 \%$. Critical values $D^{\alpha}$ for various numbers of $n$ and significance levels $\alpha$ are tabulated elsewhere $[12,13]$. If the maximum difference is less than the critical value, the proposed distribution is acceptable at the specified significance level $\alpha$.

The KS test was conducted in this study using a Statistical Package Computer Program [14,15] which gives directly the maximum (absolute) difference value, $D_{\max }$. The results are listed in Table 3.

It is evident that at a significance level of $1 \%, D$ for the samples of "individual value", maxa "average value" are less than the critical difference values of $D_{n}^{\alpha}$.

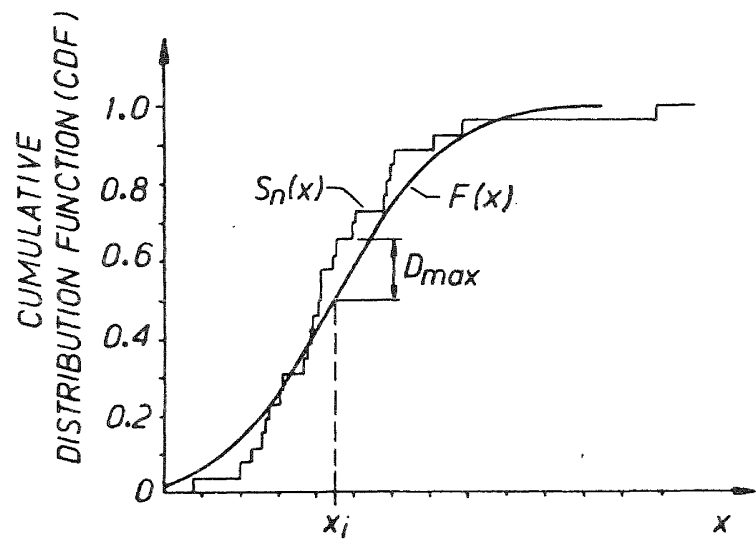

VARIATE

Fig. 10 Comparison Between Observed and Proposed Cumulative Distributions.

Even at a significance level of $10 \%, D_{\max }$ for the samples of "average value" are still less than the critical difference values. Hence it can be concluded that the assumption of a normal distribution of data is valid.

The calculated values for the mean standard deviation and coefficient variation for each population of reinforcing steel. based on the assumed normal distribution are also shown in Table 3. Using the "average value" samples as a basis, the mean yield strength of Grade 275 steel is 
321.3 MPa with coefficient of variation of $4.82 \%$, whereas for Grade 380 steel the mean yield strength is $457.8 \mathrm{MPa}$ with coefficient of variation $5.74 \%$. These results do not differ much from the statistical data of the "individual value" samples. However, the distribution of the "average value" samples show better agreement with the assumed normal distribution.

(2) Variation in the area of cross-section of the bar

Previous investigators have found that the actual cross sectional areas of reinforcing bars show some variation from the nominal areas, as a result of factors during the bar rolling process. If the determination of the steel yield strengths from the tensile test results are based on the actual areas, the effect of this variation would need to be taken into account.

However since the yield strengths of all the existing samples were based on the nominal areas as specified in NZS $3402 \mathrm{P}$ : 1973 [7], there is no need to consider the variation in bar area from the nominal area in this study.

\section{(3) Effect of bar diameter}

A possible variable affecting yield strength is bar diameter, since there may be differences arising from the rolling process. Figs. 11 and 12 show the measured yield strength values plotted against bar diameter for Grades 275 and 380 steel reinforcement, respectively. It is evident that the yield strengths for various bar diameters vary with no pattern from the smallest to the largest bar diameter. Similar results were obtained by Mirza and MacGregor in their investigation [11].

(4) Effect of the strain at which yield strength is defined

Variation in the strain at which yield strength is defined will cause some variation in the measured yield strength as discussed by Mirza and MacGregor [11]. However, this effect is irrelevant for this study, since the yield strength has been clearly defined by NZS 3402P:1973 [7], adopting the British Standard (BS) 18:1971 [17]. That definition for yield strength, followed throughout this study, is "a point of stress which is reached during the test at which plastic deformation, soon after it has been initiated, continues to occur at near constant stress".

\section{(5) Effect of loading rate}

It is necessary to consider the effect of the loading rate, since as has been discussed elsewhere $[5,8]$, rapid loading can cause a significant increase in the yield strength.

Mill tests on steel specimens are generally carried out at high loading rates. For example, Pacific steel Ltd uses a high strain rate, with maximum value of $0.0025 / \mathrm{sec}$, as specified [17], in its tests. This maximum strain rate is considerably higher than the quasi static strain rate of approximately $0.00001 / \mathrm{sec}$ which has been used in the tests at the University of Canterbury. However, since earthquake loads are dynamic by nature, it is appropriate to consider the strength results from Pacific steel Ltd in order to obtain the likely overstrength factor which might occur during a severe earthquake.

A comparison of the results obtained from the strain rate tests of Pacific steel Ltd and the quasi static strain rate tests of the University of Canterbury for Grades 275 and 380 steel are shown in Table 4. The mean of yield strength values show differences of $7.8 \%$ for Grade 275 steel and $6.5 \%$ for Grade 380 steel. These strength increases due to high strain rate are in agreement with a $7 \%$ increase in yield strength predicted using the following equation suggested by Mander et al [8] for bars in tension:

$$
\left(f_{y}\right)_{\text {dyn }}=0.953\left[1+\left(\frac{\varepsilon}{700}\right)^{1 / 6}\right]\left(f_{y}\right)_{\text {stat }}
$$

where ( $f_{Y}$ ) is the yield strength measured ady $y^{\prime}$ strain rate of $\varepsilon$, and $\left(f_{\mathrm{y}}\right)$ stat is the yield strength measured at a quasit static strain rate of $\varepsilon=0.00001 /$ sec.

\section{5 .2 Ultimate Tensile Strength, $\mathrm{f}_{\text {su }}$}

The ultimate tensile strength of the steel is a less important parameter than the yield strength. Nevertheless, as mentioned earlier, it is one of the basic parameters used to define the strain hardening region of the stress-strain curve model adopted in this study.

The correlation between the ultimate tensile strength and the yield strength is relatively strong for all grades of reinforcing steel, as can be seen in Table 5. Hence it is reasonable to assume that the sources of variation in the ultimate strength are the same as those considered for yield strength. The relevant sources of variation are discussed below.

\section{(1) Variation in the strength of the material}

The rolling of bars and/or the chemical processing will also cause some variation in the ultimate strength of reinforcing steel. NZS 3402P:1973 [7] specifies that for Grade 275 steel the minimum ultimate tensile strength for Grade 275 steel shall be less than $380 \mathrm{MPa}$ and the maximum shall not be greater than $520 \mathrm{MPa}$. For Grade $380 \mathrm{steel}$ it is specified that the minimum ultimate tensile strength shall not be less than $570 \mathrm{MPa}$, which shall not be less than 1.2 times the actual yield strength, and the maximum is not specified. All the samples analysed fulfill these requirements.

Figs. 13 and 14 show histograms of the measured ultimate strengths for Grades 275 and 380 steel, respectively, based on "average value" samples. The actual 


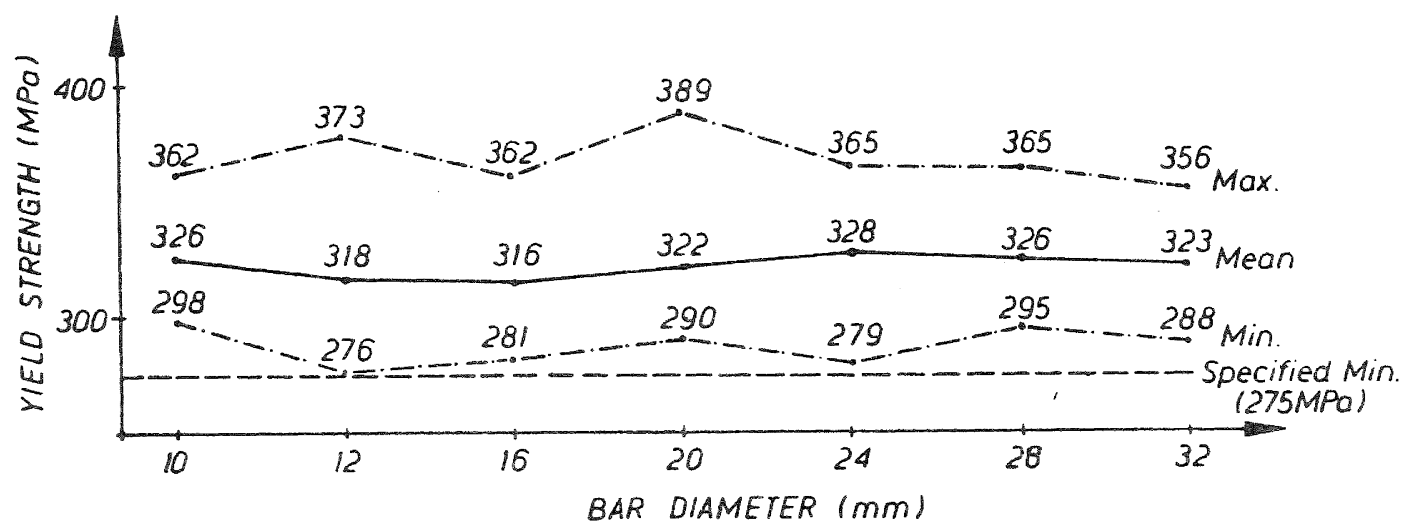

Fig. 11 Yield Strength Values of Various Deformed Bar Diameters of Grade 275 Reinforcing steel supplied by pacific steel Ltd.

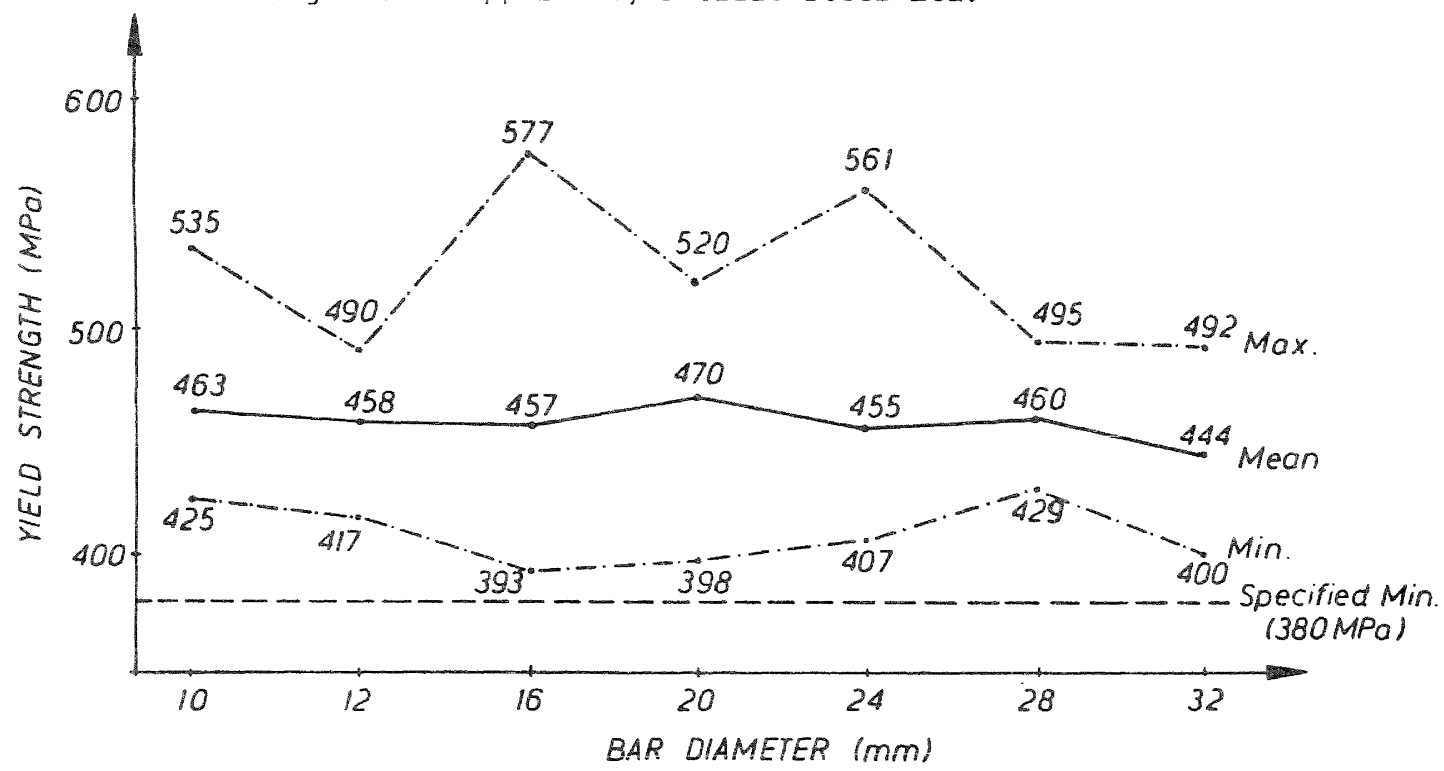

Fig. 12 Yield Strength Values of Various Deformed Bar Diameters of Grade 380 Reinforcing Steel Supplied by Pacific Steel Ltd.

TABLE 4: Comparison of Mean Yield Strengths

\begin{tabular}{|l|c|c|c|c|}
\hline \multirow{2}{*}{ Source } & \multicolumn{2}{|c|}{ Grade 275 Steel } & \multicolumn{2}{c|}{ Grade 380 Steel } \\
\cline { 2 - 5 } & $\begin{array}{c}\text { Total No. } \\
\text { of Samples }\end{array}$ & Mean f & $\begin{array}{l}\text { Total No. } \\
\text { of Samples }\end{array}$ & Mean f y \\
\hline $\begin{array}{l}\text { Pacific Steel Ltd. } \\
\text { (average value) } \\
\text { Univ. of Canterbury }\end{array}$ & 759 & 321.3 & 182 & 457.8 \\
31 & 298.0 & 25 & 430.0 \\
\hline
\end{tabular}

$\frac{\text { TABLE } 5 \text { : Linear Correlation Analysis for Mean Values of } f}{\text { Data from Pacific Steel Ltd }}$ and $f$ Based on

\begin{tabular}{|c|c|c|c|c|}
\hline \multirow{2}{*}{$\begin{array}{l}\text { Bar Diameter } \\
(\mathrm{mm})\end{array}$} & \multicolumn{2}{|c|}{ Grade 275 steel } & \multicolumn{2}{|c|}{ Grade 380 Steel } \\
\hline & Mean $\mathrm{f}_{\mathrm{y}}$ & Mean $I_{\text {su }}$ & Mean $f_{y}$ & Mean $F_{s u}$ \\
\hline $\begin{array}{l}10 \\
12 \\
16 \\
20 \\
24 \\
28 \\
32\end{array}$ & $\begin{array}{l}326 \\
318 \\
316 \\
322 \\
328 \\
326 \\
323\end{array}$ & $\begin{array}{l}446 \\
431 \\
443 \\
455 \\
461 \\
465 \\
465\end{array}$ & $\begin{array}{l}463 \\
458 \\
457 \\
470 \\
455 \\
460 \\
444\end{array}$ & $\begin{array}{l}686 \\
701 \\
685 \\
719 \\
685 \\
706 \\
679\end{array}$ \\
\hline
\end{tabular}




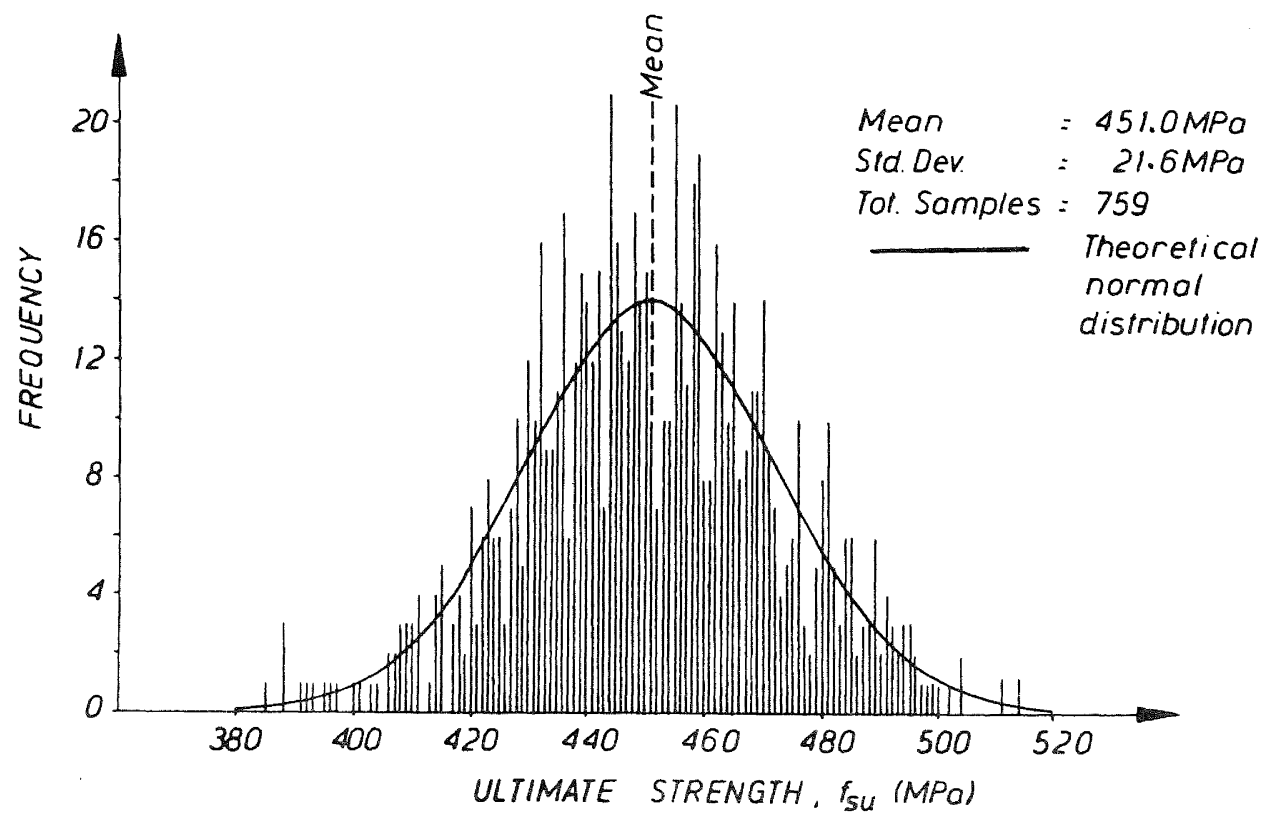

Fig. 13 Histogram of the Ultimate Strengths of Grade 275 Deformed Bar Reinforcing Steel Based on "Average Value" Samples.

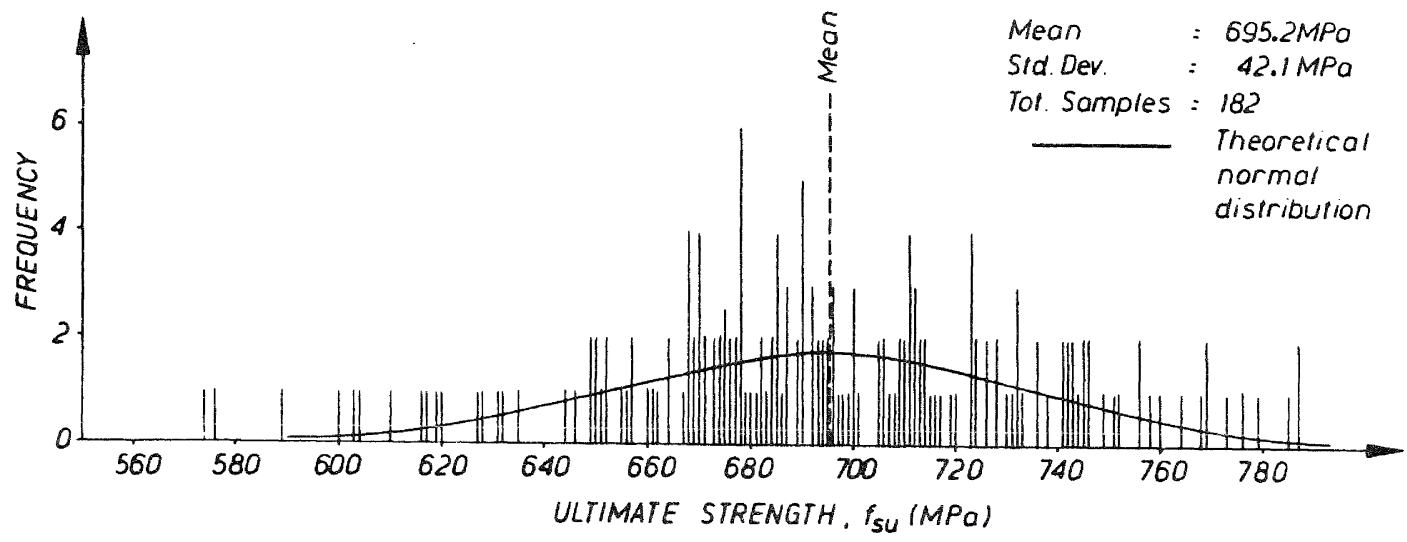

Fig. 14 Histogram of the Ultimate Strengths of Grade 380 Deformed Bar Reinforcing Steel Based on "Average Value" Samples.

distributions of the ultimate strengths show a good fit with the normal

distribution, as was shown by a statical analysis procedure similar to that used for observing the variation in steel yield strengths. The results of this analysis for ultimate strength can be seen in detail in Ref. 6. As indicated in Table 6, the KS test indicates that all observations have a maximum absolute difference ( $D$ ) less than the critical value even at max 208 level of significance. Hence it can be concluded that the assumption of a normal distribution is valid.

The calculated values for the mean, standard deviation and coefficient of variation, based on the normal distribution, are also shown in Table 6 . The mean values are 451.0 MPa for Grade 275 steel and 659. $2 \mathrm{MPa}$ for Grade 380 steel.

\section{(2) Effect of bar diameter}

As verified for the yield strength. no significant influence of bar diameter on the variation of the ultimate strength was observed. The mean ultimate strengths listed in Table 5 show that the values listed vary irregularly from the smallest to the largest bar diameter.

\section{(3) Effect of loading rate}

Mander et al [8] found that the strength of steel is magnified by the same percentage throughout the loading range due to high strain rate. Hence the magnification in ultimate strength due to fast strain rate can be taken to be given in Eq. 8 with $f$ substituted for $f$. As for yield strength, this study used ${ }^{Y}$ the data for ultimate strength obtained from high strain tests conducted by Pacific steel Ltd. 
TABLE 6 : Statistical Data for Ultimate Strength of Grades 275 and 380 Deformed Bar Reinforcing Steel

\begin{tabular}{|c|c|c|c|c|}
\hline \multirow[t]{2}{*}{ Description } & \multicolumn{2}{|c|}{ Grade 275 Steel } & \multicolumn{2}{|c|}{ Grade 380 Steel } \\
\hline & $\begin{array}{l}\text { Individual }{ }^{\star} \\
\text { Value }\end{array}$ & $\begin{array}{l}\text { Average }{ }^{\star \star} \\
\text { Value }\end{array}$ & $\begin{array}{l}\text { Individual } \\
\text { Value }\end{array}$ & $\begin{array}{l}\text { Average } \\
\text { Value }\end{array}$ \\
\hline Total Number of Samples & 1547 & 759 & 388 & 182 \\
\hline Mean, $\mathrm{f}_{\text {su }}(\mathrm{MPa})$ & 451.0 & 451.0 & 695.2 & 695.2 \\
\hline Standard Deviation (MPa) & 21.7 & 21.6 & 42.52 & 42.1 \\
\hline Coefficient of Variation $\left(\frac{\circ}{\partial}\right)$ & 4.81 & 4.79 & 6.12 & 6.06 \\
\hline Maximum Value of Data (MPa) & 515.0 & 514.0 & 789.0 & 787.5 \\
\hline Minimum Value of Data (MPa) & 385.0 & 385.5 & 567.0 & 574.0 \\
\hline Kolmogorov-Smirnov (KS) Test & & & & \\
\hline (a) Max. (absolute) Difference $D_{\max }$ & 0.222 & 0.0189 & 0.0523 & 0.0615 \\
\hline $\begin{array}{l}\text { (b) Critical Difference at significance } \\
\text { level } \alpha=18 \\
\alpha=58 \\
\alpha=108 \\
\alpha=208\end{array}$ & $\begin{array}{l}0.0414 \\
0.0346 \\
0.0310 \\
0.0272\end{array}$ & $\begin{array}{l}0.0592 \\
0.0494 \\
0.0443 \\
0.0388\end{array}$ & $\begin{array}{l}0.0827 \\
0.0690 \\
0.0619 \\
0.0543\end{array}$ & $\begin{array}{l}0.1208 \\
0.1008 \\
0.0904 \\
0.0793\end{array}$ \\
\hline
\end{tabular}

Notes * All existing samples are considered as individuals.

* Only average values of each cast from Pacific Steel Ltd are considered

\section{5 .3 Strain at Which the Strain Hardening Commences, ${ }^{E}$ sh}

This parameter makes an important contribution to the determination of the overstrength factor. For reinforcing steels with a short yield plateau, that is

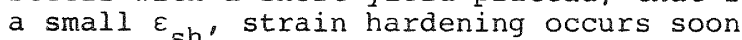
after yielding and the steel stress may reach a considerably higher value than the yield strength during a major earthquake. This in turn will cause a large increase in the flexural capacity of the member and, as a consequence, a higher overstrength factor needs to be employed in design.

The study of the variation of $\varepsilon$ sh was based on only 28 samples of Grade 275 steel and 18 samples of Grade 380 steel measured at the University of Canterbury during the last 10 years during reinforced concrete research projects involving New zealand manufactured reinforcing bars. No data on this parameter was provided by Pacific Steel Ltd. The actual distributions of this parameter are shown in Figs. 15 and 16. Statistical analysis, similar to that used for observing the variation in yield strength, showed that the distributions gave a good fit with the standard distribution, as indicated by the kS test [6]. Table 7 lists the calculated statistical parameters. The mean values for $\varepsilon$ are 0.022 for Grade 275 steel and $0.0099^{\text {h }}$ for Grade 380 steel. The ratio of mean $\varepsilon_{\text {sh }}$ to the mean yield strain $\mathrm{f}_{\mathrm{y}} / \mathrm{E}_{\mathrm{s}}$ is 13.7 for Grade 275 steel and 4.2 for Grade 380 steel. It is evident that Grade 380 steel has a much shorter yield plateau than Grade 275 steel.

\section{5 .4 Ultimate Strain, $\varepsilon_{\text {su }}$}

Knowledge of the ultimate strain, defined here as the strain at which the stress reaches the maximum value, is necessary in order to define the stressstrain curve in the strain hardening range. Unfortunately only 8 samples for Grade 275 steel and 3 samples for Grade 380 steel were available from University of

Canterbury tests on New Zealand manufactured reinforcing bars. For these samples the average ultimate strain was 0.202 for Grade 275 steel and 0.153 for Grade 380 steel. It is assumed that rate of loading does not affect the value for ultimate strain.

\subsubsection{Modulus of Elasticity, $E_{S}$}

Statistical analysis based on 45 samples obtained from quasi static tests at the University of Canterbury on New Zealand manufactured reinforcing bars of Grades 275 and 380 steel gave a mean value for $E_{s}$ of $205.2 \mathrm{GPa}$.

The data for this parameter can be considered as normally distributed, since the actual distributions show good agreement with the proposed normal distribution model as indicated by the KS test. Table 8 reveals this fact, together with the other statistical parameters.

In this study the modulus of elasticity at a high strain rate $(0.0025 / \mathrm{sec})$ was used. To obtain this value the mean quasi static value of $E$ was multiplied by a dynamic magnification factor as suggested by Mander et al [8] to give the value for the dynamic $E_{s}$ shown in Table 8.

\subsubsection{Strain Hardening Modulus, E sh}

Statistical analysis based on 45 samples obtained from quasi static tests at the University of Canterbury on New Zealand made reinforcing bar gave a mean value for $E_{\text {of }} 4,921 \mathrm{MPa}$ for Grade 275 steel and 8,391 for Grade 380 steel. 


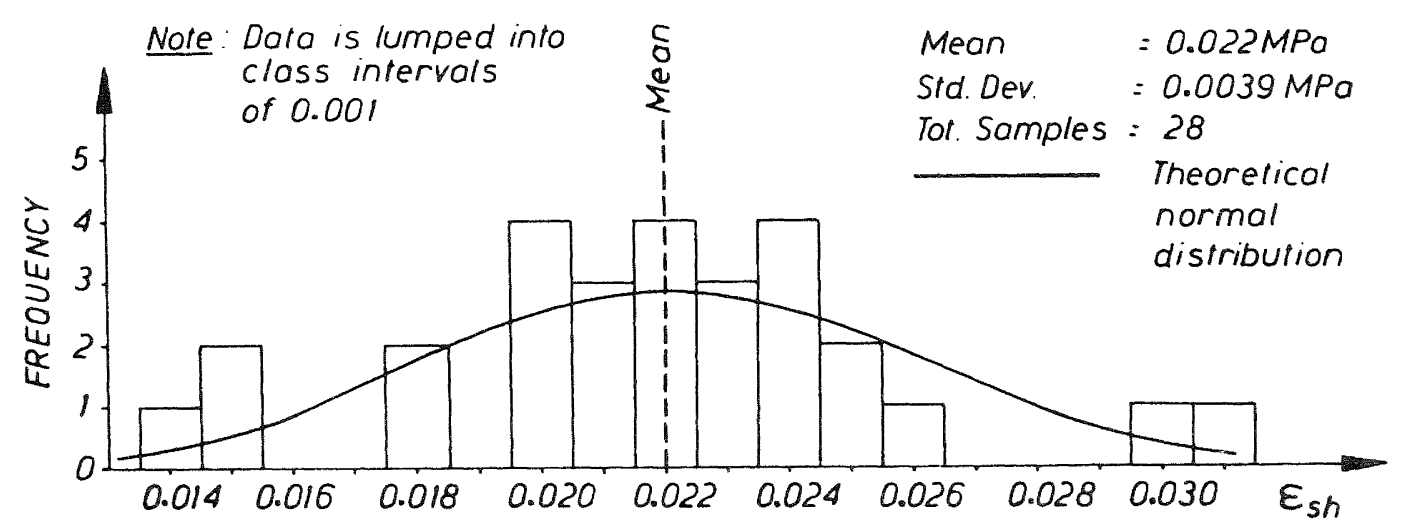

Fig. 15 Histogram of Strain Hardening Strains of Grade 275 Deformed Bar Reinforcing Steel (Data is lumped into class intervals of 0.001 )

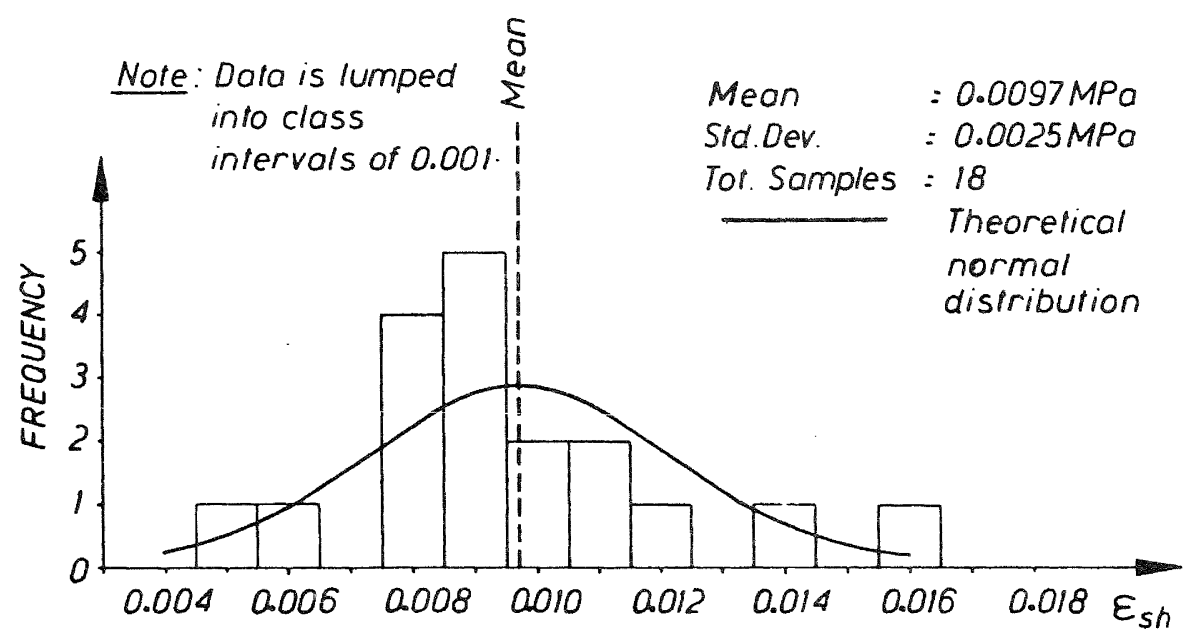

Fig. 16 Histogram of Strain Hardening Strains of Grade 380 Deformed Bar Reinforcing steel. (Data is lumped into class intervals of 0.001 ). $\frac{\text { TABLE } 7 \text { : Statistical Data for } \varepsilon}{\text { Bar Reinforcing Steel }}$ sh of Grades 275 and 380 Deformed

\begin{tabular}{|l|l|l|}
\hline Description & $\begin{array}{l}\text { Grade 275 } \\
\text { Steel }\end{array}$ & $\begin{array}{l}\text { Grade 380 } \\
\text { Steel }\end{array}$ \\
\hline Total Number of Samples & 28 & 18 \\
Mean Esh & 0.0220 & 0.0097 \\
Standard Deviation & 0.0039 & 0.0025 \\
Coefficient of Variation (8) & 17.6 & 25.6 \\
Maximum Value & 0.0308 & 0.0160 \\
Minimum Value & 0.0143 & 0.0055 \\
\hline Kolmogorov-Smirnov Test & & 0.154 \\
(a) Max. (absolute) Difference & 0.130 & 0.246 \\
(b) Critical Difference at $\alpha=20 \%$ & 0.198 & \\
\hline
\end{tabular}


TABLE 8 : Statistical Data for Young's Modulus $E_{S}$ of Grades 275 and 380 Deformed Bar Reinforcing Steel

\begin{tabular}{|l|c|}
\hline \multicolumn{1}{|c|}{ Description } & $\begin{array}{c}\text { Grades } 275 \text { and } \\
380 \text { Steel }\end{array}$ \\
\hline Total Number of Samples & 45 \\
Mean E (MPa) & 205,200 \\
Standard Deviation (MPa) & $919,560)$ \\
Coefficient of Variation (o) & 9,720 \\
Maximum Value of Data (MPa) & 4.74 \\
Minimum Value of Data (MPa) & 224,700 \\
\hline Kolmogorov-Smirnov (KS) Test & 185,000 \\
\hline $\begin{array}{l}\text { (a) Maximum (abs.) Difference } \\
\text { (b) Critical Difference at }\end{array}$ & 0.0804 \\
\hline
\end{tabular}

Note: * ( ) indicates the theoretical mean value for the dynamic $E_{S}$ for a strain rate of $0.0025 / \mathrm{sec}$.

TABLE 9: Statistical Data for Strain Hardening Modulus E sh of Grades 275 and 380 Deformed Bar Reinforcing steel

\begin{tabular}{|l|c|c|}
\hline \multicolumn{1}{|c|}{ Description } & Grade 275 Steel & Grade 380 Steel \\
\hline Total Number of Samples & 28 & 17 \\
Mean Esh (MPa) & 4921.4 & 8391.2 \\
Standard Deviation (MPa) & $(5265.9)$ & $(8978.6)$ \\
Coefficient of Variation (\%) & 1080.4 & 1497.8 \\
Maximum Value of Data (MPa) & 21.95 & 17.85 \\
Minimum Value of Data (MPa) & 7400 & 11200 \\
\hline Kolmogorov-Smirnov Test & 3500 & 6000 \\
\hline (a) Max. (absolute) Difference & 0.1602 & 0.1176 \\
(b) Critical Difference at $\alpha=20 \%$ & 0.1980 & 0.2540 \\
\hline
\end{tabular}

Note: * ( ) indicates the mean value for the dynamic $E_{\text {sh }}$ for a strain rate of $0.0025 / \mathrm{sec}$.

Analysis of this data shows a good fit with a normal distribution. Table 9 lists the other statistical data for this parameter, together with its mean dynamic values based on the stiffness enhancement due to rapid loading, as mentioned for $E_{\text {. }}$. These mean dynamic values will be used in the study.

\subsection{Variability of the Yield Strength of Transverse Reinforcing steel, $f_{y h}$}

The theoretical moment-curvature analyses conducted in this study considered reinforced concrete sections with code specified quantities of transverse confining reinforcement. When high compressive strains develop in the concrete the transverse reinforcement becomes significantly stressed and the confining pressure is a function of its yield strength, fyh.
The statistical analysis for the measured yield strength of transverse reinforcement is based on 352 samples from pacific Steel Ltd. All the samples are plain round bars of Grade 275 steel of $10 \mathrm{~mm}$ and $12 \mathrm{~mm}$ diameter. Again, the two values of $f$ from the same cast numbers showed non-significant differences. Therefore, the statistical analysis was based on the "average value" samples and, as a consequence, the total number of samples was reduced to 176 . The observed data showed good agreement with the normal distribution and this is supported by the KS test which shows that the maximum (absolute) difference $\left(D_{\max }=0.0442\right)$ is much less than the critical value, even at a $20 \%$ significance level. The mean yield strength is $331.1 \mathrm{MPa}$, as listed in Table 10 together with other statistical data. In this case, again, the data is for a high loading rate with a maximum value of $0.0025 / \mathrm{sec}$. However, since 
TABLE 10: Statistical Data for Yield Strength of Transverse Reinforcement of Grade 275 Plain Round Bar Steel

\begin{tabular}{|l|c|}
\hline \multicolumn{1}{|c|}{ Description } & $\begin{array}{c}\text { Grade 275 Steel } \\
\text { (average values) }\end{array}$ \\
\hline Total Number of Samples & 176 \\
Mean fyh (MPa) & 331.1 \\
Standard Deviation (MPa) & 16.0 \\
Coefficient of Variation (o) & 4.83 \\
Maximum Value of Data (MPa) & 372.0 \\
Minimum Value of Data (MPa) & 283.0 \\
\hline Kolmogorov-Smirnov Test & 0.0442 \\
(a) Max. (absolute) Difference & 0.0806 \\
(b) Critical Difference at $\alpha=20 \%$ & \\
\hline
\end{tabular}

earthquake loading is dynamic by nature this fast loading rate simulates loading as might occur during a severe earthquake.

\subsection{Range of Steel Parameters Used in Moment-Curvature Analyses}

For the theoretical moment-curvature analyses using Monte Carlo simulations, described in the next section, a range of probable values for each of the six

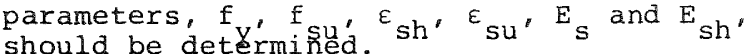

Based on the statistical study it is assumed that the range for all parameters is from the $5 \%$ lower tail of probability to the $95 \%$ upper tail of probability, except for the ultimate strain where the average values are taken and for the yield strength of Grade 380 steel where the range is determined from $5 \%$ to $98 \%$. This adjustment for the yield strength of Grade 380 steel is made because its sample distribution is more skewed to the right hand side and has a longer upper tail than the distributions of other parameters.

To incorporate the uncertainty about the true mean values, especially for parameters with small number of samples, a confidence interval of mean value is determined and then the range values, as mentioned above, are calculated based on this mean interval.

The confidence interval of mean is a measure of the uncertainty associated with incomplete knowledge of the true mean of the population. A confidence interval of mean at a certain degree of confidence, say $95 \%$ as used in this study, indicates the probability that the true mean lies in the listed interval is 0.95. A large sample confidence interval for the mean of a normal population can be denoted by:

$$
x_{m} \pm \frac{z_{\alpha / 2} s}{\sqrt{n}}
$$

where $x_{m}$ is the sample mean, $s$ is the sample standard deviation, $n$ is the total number of sample values, $\mathrm{z}$ is the percentiles of the standard normal distribution, as tabulated in most statistics text-books, and $(I-\alpha)$ indicates the degree of confidence. If the sample size is small, a slight modification should be made so that the confidence interval for the mean of a normal population is:

$$
x_{m} \pm \frac{t_{\alpha / 2, n-1^{s}}}{\sqrt{n}}
$$

where $x_{m}, s$ and $n$ are defined above, $t$ is the permentiles of the "t-distribution" with $(n-1)$ degrees of freedom as tabulated elsewhere $[13,18]$.

The range values, based on $5 \circ$ lower tail to $95 \%$ upper tail of normal probabilities, are calculated as follows. For large size samples, for example $f_{y}$ of Grade 275 steel of this study:

5 Lower Tail Value = lower limit of Mean -

$\mathrm{Z}(\phi) \times$ Standard Deviation $=320.2$ -

$1.645 \times 15.5=295 \mathrm{MPa}$

$95 \%$ Upper Tail Value = upper limit of Mean + $Z(\phi) \times$ Standard Deviation $=322.4+$ $1.645 \times 15.5=348 \mathrm{MPa}$

where $\pm Z(\phi)$ indicates the upper and lower limits of the standard normal distribution based on the corresponding probability as tabulated elsewhere. For small size samples (that is, approximately less than 30), for example $E_{\text {hh }}$ of Grade 275 steel in this study:

5\% Lower Tail Value = lower limit of Mean $t(\phi) \times$ Standard Deviation $=4818.0-$ $1.701 \times 1156.0=2852 \mathrm{MPa}$

95: Upper Tail Value = upper limit of Mean $t(\phi) \times$ Standard Deviation $=5713.0+$ $1.701 \times 1156.0=7679 \mathrm{MPa}$

where $t(\phi)$ is based on the t-distribution as tabulated elsewhere, rather than the standard normal distribution.

By considering the confidence interval of mean in these calculations it is intended that a more conservative range of values is obtained rather than those based on the sample mean and standard deviation which are estimated as the population parameters. 
TABLE 11 : Statistical Data for Basic Parameters of the Stress-Strain Relation of Deformed Bar Reinforcing Steel Based on the $5 \%$ Lower Tail and 958 Upper Tail of Normal Probability

\begin{tabular}{|c|c|c|c|c|c|c|}
\hline Parameter & $\begin{array}{l}\text { Yield } \\
\text { Strength } \\
\mathrm{f}_{\mathrm{y}}\end{array}$ & $\mid \begin{array}{c}\text { Ultimate } \\
\text { Strength } \\
\text { f su }\end{array}$ & $\begin{array}{l}\text { Str.Hard. } \\
\text { Strain } \\
\varepsilon_{\text {sh }} \\
\end{array}$ & $\begin{array}{l}\text { Ultimate } \\
\text { Strain } \\
{ }^{E} \text { su }\end{array}$ & $\begin{array}{c}\text { Young's } \\
\text { Modulus } \\
E_{s}\end{array}$ & $\begin{array}{l}\text { Str. Hard. } \\
\text { Modulus } \\
E_{\text {sh }}\end{array}$ \\
\hline Grade 275 Lower 5\% Tail & $295 \mathrm{MPa}$ & $414 \mathrm{MPa}$ & 0.014 & $0.202^{*}$ & $199400 \mathrm{MPa}$ & $2852 \mathrm{MPa}$ \\
\hline Grade 275 Upper $95 \%$ Tail & $348 \mathrm{MPa}$ & $488 \mathrm{MPa}$ & 0.030 & $0.202^{*}$ & $239700 \mathrm{MPa}$ & $7679 \mathrm{MPa}$ \\
\hline Grade 380 Lower $5 \%$ Tail & $410 \mathrm{MPa}$ & $620 \mathrm{MPa}$ & 0.004 & $0.153^{*}$ & $199400 \mathrm{MPa}$ & $5369 \mathrm{MPa}$ \\
\hline Grade 380 Upper $95 \%$ Tail & $516 \mathrm{MPa}^{* *}$ & $770 \mathrm{MPa}$ & 0.015 & $0.153^{*}$ & $239700 \mathrm{MPa}$ & $12588 \mathrm{MPa}$ \\
\hline
\end{tabular}

Notes: * Average values, not tail values

* Upper $98 \%$ tail, not upper $95 \%$ tail.

Table 11 lists the calculated range values for the deformed bar reinforcement. These values were used for the longitudinal reinforcement in the theoretical momentcurvature analyses.

Range values from the $5 \%$ lower tail value to the $95 \%$ upper tail value, considering the interval of mean, were also found for the plain round 10 and 12 mm diameter Grade 275 steel as $299 \mathrm{MPa}$ and $360 \mathrm{MPa}$. This plain round steel was used as transverse reinforcement in the momentcurvature analyses.

The use of a yield strength below which not more than $5 \%$ of the test results fall (that is, the $5 \%$ lower tail values, namely $295 \mathrm{MPa}$ and $410 \mathrm{MPa}$ for Grades 275 and 380 deformed reinforcing steel, respectively) appears a reasonable basis for strength design when determining the dependable strength of members. It is unduly conservative to use in design a value for the yield strength above which all test results fall as is currently the practice in New Zealand. Note that according to NZS 3402P:1973 [7] no test results for yield strength are permitted to fall beneath $275 \mathrm{MPa}$ for Grade 275 steel or $380 \mathrm{MPa}$ for Grade 380 steel. The $5 \%$ lower tail value is currently used in European and British codes when defining the characteristic yield strength which is used in design. The overstrength factors for the steel stress could then be related to the $5 \%$ lower tail values rather than the more conservative minimum values, leading to smaller overstrength factors.

3. THEORETICAL MOMENT-CURVATURE ANALYSES TO DETERMINE OVERSTRENGTH FACTORS

\subsection{General}

In the capacity design procedure of earthquake resistant structures it is necessary to determine the maximum likely flexural strengths, referred to as the "flexural overstrengths", of the plastic hinge regions of members. This is so adequate strength can be provided in the remainder of the structure to avoid brittle failure. For example, the design shear forces in the beams, columns, and beam-column joints will be a function of the overstrength moments at the plastic hinges and will be greater than the actions calculated using the design factored loads of the code.

In the following sections results are presented of a study conducted to reevaluate the values of the flexural overstrength factors currently used in seismic design in New Zealand. Theoretical momentcurvature analyses, based on the actual measured steel properties, were carried out for a range of different section shapes and reinforcement configurations. For this purpose, the probable variability of the material properties were considered by incorporating Monte Carlo Simulation Techniques. For the reinforcing steel, the results obtained from the statistical study presented earlier were used in these analyses. The likely variation of concrete compressive strength was considered as well, based on the Specification for concrete Construction, NZS 3109:1980 [19].

\subsection{Moment-Curvature Analyses}

Moment-curvature analyses of sections enables the moment of resistance of members over a range of curvatures to be calculated, thus permitting the change in moment capacity with plastic hinge rotation to be assessed [4]. The curvature of a member is defined as the rotation per unit length. The moment-curvature curve for a reinforced concrete section can be traced theoretically using the requirements of strain compatibility and equilibrium of internal forces [4] .

Fig. 17 shows a typical momentcurvature relation derived for a reinforced concrete section subjected to monotonic loading. The moment resisted by the section at curvatures greater than when yield is first reached in the longitudinal tension steel depends on the configuration of reinforcement in the section, and on the stress-strain relations for the steel reinforcement and the compressed concrete.

Several previous studies have been conducted to determine the moment-curvature behaviour of reinforced concrete sections subjected to cyclic loading, simulating the effect of seismic loading. Examples of the theoretical and experimental investigations of cyclic moment-curvature behaviour are described elsewhere $[4,5,8]$. 


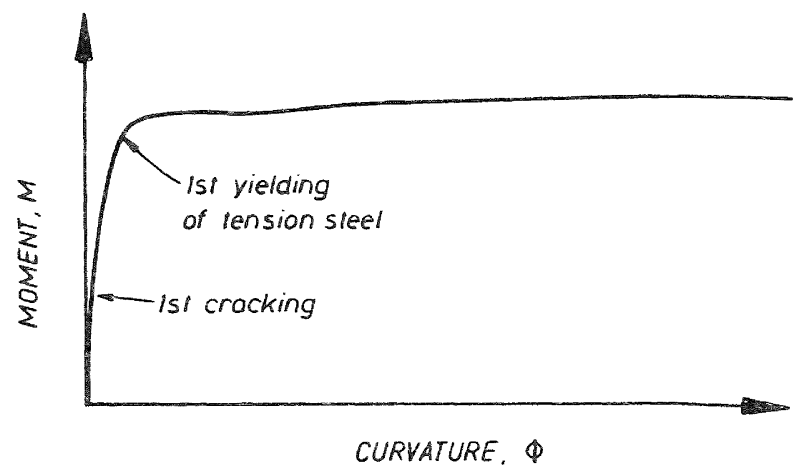

Fig. 17 Moment-Curvature Relation for a Reinforced Concrete section.

It is of interest that during the cyclic (reversed) loading, stiffness degradation will occur due to the Bauschinger effect of the reinforcing steel (see Section 2.2) and due to the full depth open flexural cracks in the concrete which will exist during parts of the loading cycles. Previous investigations have shown, however, that the monotonic moment-curvature relationship for beams gives a good indication of the envelope curve for cyclic moment-curvature behaviour. That is, although the flexural stiffness is reduced during cyclic loading the beam will reach the monotonic moment capacity at higher curvatures. In the case of columns with high compressive loads the maximum moment capacity reached may reduce with cyclic loading due to deterioration of the concrete stress-strain behaviour. However again the monotonic moment-curvature relationship will give a good envelope curve for cyclic moment-curvature behaviour of columns. It should also be noted that previous investigations have indicated that experimentally obtained moment-curvature relationships can be predicteo accurately by theoretical analyses $[4,5,8]$.

This study uses theoretical monotonic moment-curvature relationships to predict the maximum likely moment capacity of reinforced concrete members. The moment-curvature analyses are based on the following assumptions:

a) Plane sections remain plane after bending.

b) The stress-strain relationships for the reinforcing steel and the unconfined and confined concrete are as described in section 3.3.

c) When the concrete tensile stress exceeds the tensile strength the concrete is assumed to crack and to be incapable of carrying tension thereafter.

d) There is no bond slip between the longitudinal reinforcing steel and the core concrete.

3.3 Material Properties Assumed in the Moment-Curvature Analyses

\subsubsection{Steel Reinforcement}

The stress-strain model proposed by
Mander et al [8], defined by Eqs. 1, 2, 4 and 6 and illustrated in Fig. 4, was adopted.

The statistical studies described in section 2 give the means, coefficients of variation, and the range of values assuming a normal distribution for the

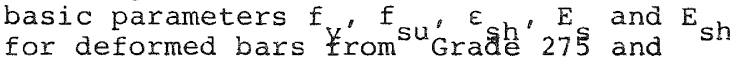
for deformed bars rom Grade 275 and reinforcement in this study. For $\varepsilon_{\text {su }}$ only the average values were considered since the total number of test samples was Iimited.

The statistical studies described in Section 2 also give the means, coefficients of variation and range of values assuming a normal distribution for Grade 275 plain round bars considered as transverse reinforcement in this study.

The steel properties used are based on those measured at a strain rate of $0.0025 /$ second, in order to include the effect of dynamic loading during earthquakes.

\subsubsection{Concrete}

The stress-strain model proposed by Mander et a] [8] for confined and unconfined concrete under monotonic compressive loading was adopted. The model is illustrated in Fig. 18. The stress-strain relationship may be written as follows:

$$
f_{C}=\frac{f_{C C} \times r}{r-1+x^{r}}
$$

where $\mathrm{f}_{\text {= longitudinal concrete stress }}$ $F_{C C}^{G}=$ confined compressive strength of concrete, which is dependent on the quantity, arrangement and yield strength of the transverse confining reinforcement

$f_{c}^{\prime}=$ compressive strength of unconfined concrete

$\mathrm{x}=\varepsilon_{\mathrm{C}} / \varepsilon_{\mathrm{CC}}$

$\varepsilon_{c}=$ longitudinal concrete strain

$\varepsilon_{\mathrm{Cc}}=\varepsilon_{\mathrm{co}}\left[1+5\left(\frac{f_{c c}^{\prime}}{f_{c}^{\prime}}-1\right)\right]$

$\varepsilon_{c o}=$ longitudinal concrete strain when maximum unconfined concrete strength $f^{\prime}$ is reached, assumed to ${ }^{c}$ be 0.002

$$
x=\frac{E_{C}}{E_{C}-E_{\text {sec }}}
$$

where $E_{C}=5000 \sqrt{f_{C}} \mathrm{MPa}$

is the tangent modulus of elasticity of the concrete, and

$$
E_{\text {Sec }}=\mathrm{f}_{\mathrm{CC}}^{\prime} / \varepsilon_{\mathrm{CC}}
$$

To define the stress-strain behaviour of the cover concrete loutside the confined core concrete) the part of the falling branch in the region where $\varepsilon_{c_{1}}>2 \varepsilon \mathrm{co}$ is 
reaches zero stress at the spalling strain, 'sp' assumed to be 0.006 in this study.

To determine the confined compressive strength of the concrete, $f{ }^{\prime}$, Mander et al [8] have proposed a numeriç̣ analysis based on an ultimate strength surface criterion for concrete under a general multiaxial state of stress. That procedure was incorporated in the moment-curvature computer program [6]. A summary of the method for determining $f_{C C}^{\prime}$ may also be found elsewhere [20].

The concrete parameters were adjusted to apply to a strain rate of $0.0025 /$ second which was used in the steel tests. previous investigators have found that loading at a rapid strain rate will result in an increase in both the strength $f^{\prime}$ and stiffness $E$ of concrete, but a reduction in the strain $\varepsilon$ at the peak stress. In this study the modifications for strain rate proposed by Mander et al [8] were used.

For design purposes the compressive strength of concrete is based on the specified cylinder strength at 28 days. However to ensure that the specified strengths are achieved, the actual strengths are generally higher than specified. NZS 3109:1980 [19] states minimum target mean strengths as well as the coefficients of variation for each specified concrete strength for several conditions. The statistical data listed in Table 12 for concrete with specified strengths of 20 and $30 \mathrm{MPa}$ were used in this study. Table 12 assumes a high grade concrete with an established and acceptable performance record of production. A normal distribution of strengths was assumed in Table 12 .

It should be noted that the concrete stress-strain properties will have a much lesser influence on the flexural overstrength factors for reinforced concrete beams than the steel stress-strain properties.

\subsection{Section Shapes and Reinforcement Configurations}

In order to investigate the likely flexural overstrength factors which could occur in plastic hinge regions, beams with rectangular and $T$ sections and columns with square sections were considered in this study. In the case of the $T$ beams the overhanging slab width each side of the web was taken as 4 times the slab thickness.

Tables 13, 14 and 15 list the sixteen configurations of the section properties considered for each of the three beam sections analysed. Typical beam section dimensions were chosen. The combinations involved two grades of reinforcing steel, two grades of concrete, two longitudinal tension steel ratios $\rho$, and two ratios of longitudinal compression steel to tension areas $\rho^{\prime} / \rho$. The requirements of NZS 3101 [2] for potential plastic hinge regions were complied with. For example, sections with $\rho^{\prime} / \rho$ less than 0.5 were not included, and the permitted upper limit of $\rho$ was not exceeded.
TABLE 12 : Statistical Data Assumed for Concrete Compressive Strength

\begin{tabular}{|l|l|l|}
\hline \multicolumn{1}{|c|}{ Description } & \multicolumn{2}{|c|}{ Specified Strength } \\
\cline { 2 - 3 } & $20 \mathrm{MPa}$ & $30 \mathrm{MPa}$ \\
\hline $\begin{array}{l}\text { Minimum target of } \\
\text { Mean Strength (MPa) } \\
\begin{array}{l}\text { Coefficient of } \\
\text { Variation (8) }\end{array}\end{array}$ & 27.5 & 40.0 \\
$\begin{array}{l}\text { 58 Lower Tail } \\
\text { Value (MPa) or } \\
\text { Specified Strength } \\
\text { 95o Upper Tail } \\
\text { Value (MPa) }\end{array}$ & 20.0 & 13.0 \\
\hline
\end{tabular}

Each beam was analysed using two different arrangements of transverse confining steel namely:

(a) Rectangular hoop/s or $10 \mathrm{~mm}$ diameter plain round bar of Grade 275 steel with centre to centre spacing equal to six times the diameter of longitudinal bar or a quarter of the beam effective depth $(\mathrm{d} / 4)$, whichever is smaller.

(b) Rectangular hoop/s of $12 \mathrm{~mm}$ diameter plain round bar of Grade 275 steel with centre to centre spacing equal to $50 \mathrm{~mm}$. The second quantity of hoop/s provides a higher level of confinement than the first.

The details of the square columns analysed are listed in Table 16. Two levels of axial load were applied and the sections were subjected to uniaxial bending. The transverse reinforcing steel provided was that specified for confinement by Eqs: 6.24 and 6.25 of NZS 3101 [2]

\subsection{Determination of the Flexural Overstrength Factors}

\subsubsection{The Computer Program}

A computer program equipped with a Monte Carlo simulation procedure was used to derive the moment-curvature relationships of the beam and column sections taking into account the possible combinations of the material properties that might occur in reinforced concrete structures [6]. A simplified flow chart, shown in Fig. 19, illustrates how the computer program proceeds with the Monte Carlo simulation procedure for each set of section properties.

\subsubsection{Input Data for Each Set of Section Properties}

There are seven variable parameters describing the material properties involved in each moment-curvature analysis. Five of the variable parameters are required to form the stress-strain model for the longitudinal reinforcing steel, namely the yield strength, $f$, ultimate strength, f $E$, modulus of elasticity $E$, and strain hărdening modulus $E_{\text {. The }}$. Thimate strain $\varepsilon_{\text {su }}$ was assumed to be a non-variable parameter by taking the average values. 
TABLE 13 : Section Properties of T-Beams With Positive Moment

\begin{tabular}{|c|c|c|c|c|c|c|c|}
\hline $\begin{array}{l}\text { Steel } \\
\text { Grade }\end{array}$ & $\begin{array}{c}\text { Concrete } \\
\mathrm{f}_{\mathrm{C}}^{\prime}\end{array}$ & $\rho^{\prime} / \rho$ & $\begin{array}{c}\rho \\
(q)\end{array}$ & $\begin{array}{l}\mathrm{b}_{\mathrm{w}} \\
(\mathrm{mm})\end{array}$ & $\begin{array}{l}\mathrm{d} \\
(\mathrm{mm})\end{array}$ & $\begin{array}{l}\mathrm{A}_{\mathrm{S}}^{\prime} \\
\text { (top) }\end{array}$ & $\begin{array}{l}{ }_{\text {(bottom) }} \\
\text { (botol }\end{array}$ \\
\hline \multirow{8}{*}{$\begin{array}{c}\text { Grade } \\
275 \\
\text { steel }\end{array}$} & \multirow{4}{*}{$20 \mathrm{MPa}$} & \multirow{2}{*}{0.50} & 0.75 & 400 & 670 & $\begin{array}{l}\text { 2D16+ } \\
8 \mathrm{DlO}\end{array}$ & $10 D 16$ \\
\hline & & & $1.46^{\star}$ & 250 & 550 & $\begin{array}{l}3 \mathrm{D} 16+ \\
6 \mathrm{D} 10\end{array}$ & 10016 \\
\hline & & \multirow{2}{*}{1.00} & 0.75 & 250 & 535 & $\begin{array}{l}3 \mathrm{D} 16+ \\
6 \mathrm{DlO}\end{array}$ & $5 \mathrm{D} 16$ \\
\hline & & & 1.50 & 250 & 535 & $\begin{array}{l}8 \mathrm{Dl6+} \\
6 \mathrm{Dl0}\end{array}$ & 10016 \\
\hline & \multirow{4}{*}{$30 \mathrm{MPa}$} & \multirow{2}{*}{0.50} & 0.75 & 400 & 670 & $\begin{array}{l}2 \mathrm{Dl6+} \\
8 \mathrm{DlO}\end{array}$ & $10 \mathrm{D} 16$ \\
\hline & & & 1.50 & 250 & 535 & $\begin{array}{l}3 \mathrm{Dl} 6+ \\
6 \mathrm{DlO}\end{array}$ & 10016 \\
\hline & & \multirow{2}{*}{1.00} & 0.75 & 250 & 535 & $\begin{array}{l}3 \mathrm{Dl6+} \\
6 \mathrm{DlO}\end{array}$ & $5 \mathrm{Dl} 6$ \\
\hline & & & 1.50 & 250 & 535 & $\begin{array}{l}8 \mathrm{D} 16+ \\
6 \mathrm{D} 10\end{array}$ & $10 \mathrm{Dl} 6$ \\
\hline \multirow{8}{*}{$\begin{array}{c}\text { Grade } \\
380 \\
\text { steel }\end{array}$} & \multirow{4}{*}{$20 \mathrm{MPa}$} & \multirow{2}{*}{0.50} & & 400 & 670 & $\begin{array}{l}2 \mathrm{DH} 16+ \\
8 \mathrm{DH} 10\end{array}$ & $10 \mathrm{DH} 16$ \\
\hline & & & $\begin{array}{r}1.46 \star \\
= \\
\end{array}$ & 250 & 550 & $\begin{array}{l}3 \mathrm{DH} 16+ \\
6 \mathrm{DH} 10\end{array}$ & $10 \mathrm{DH} 16$ \\
\hline & & \multirow{2}{*}{1.00} & 0.75 & 250 & 535 & $\begin{array}{l}3 \mathrm{DH} 16+ \\
6 \mathrm{DH} 10\end{array}$ & $5 \mathrm{DH} 16$ \\
\hline & & & 1.50 & 250 & 535 & $\begin{array}{l}8 \mathrm{DH} 16+ \\
6 \mathrm{DH} 10\end{array}$ & $10 \mathrm{DH} 16$ \\
\hline & \multirow{4}{*}{$30 \mathrm{MPa}$} & \multirow{2}{*}{0.50} & 0.75 & 400 & 670 & $\begin{array}{l}2 \mathrm{DH} 16+ \\
8 \mathrm{DH} 10\end{array}$ & $10 \mathrm{DH} 16$ \\
\hline & & & 1.50 & 250 & 535 & $\begin{array}{l}3 \mathrm{DH} 16+ \\
6 \mathrm{DH} 10\end{array}$ & $10 \mathrm{DH} 16$ \\
\hline & & \multirow{2}{*}{1.00} & 0.75 & 250 & 535 & $\begin{array}{l}3 \mathrm{DH} 16+ \\
6 \mathrm{DH} 10\end{array}$ & $5 \mathrm{DH} 16$ \\
\hline & & & 1.50 & 250 & 535 & $\begin{array}{l}8 \mathrm{DHl} 6+ \\
6 \mathrm{DH} 10\end{array}$ & $10 \mathrm{DH} 16$ \\
\hline
\end{tabular}

Notes:

* $\rho_{\max }$ in accordance with NzS3101:1982

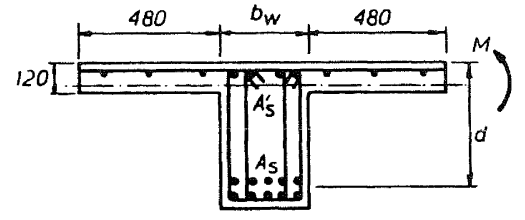

$\rho=\frac{{ }^{A} s}{b_{w}^{d}}$
$\rho^{\prime}=\frac{A_{s}^{\prime}}{b_{w}^{d}}$ 
TABLE 14 : Section Properties of T-Beams With Negative Moment

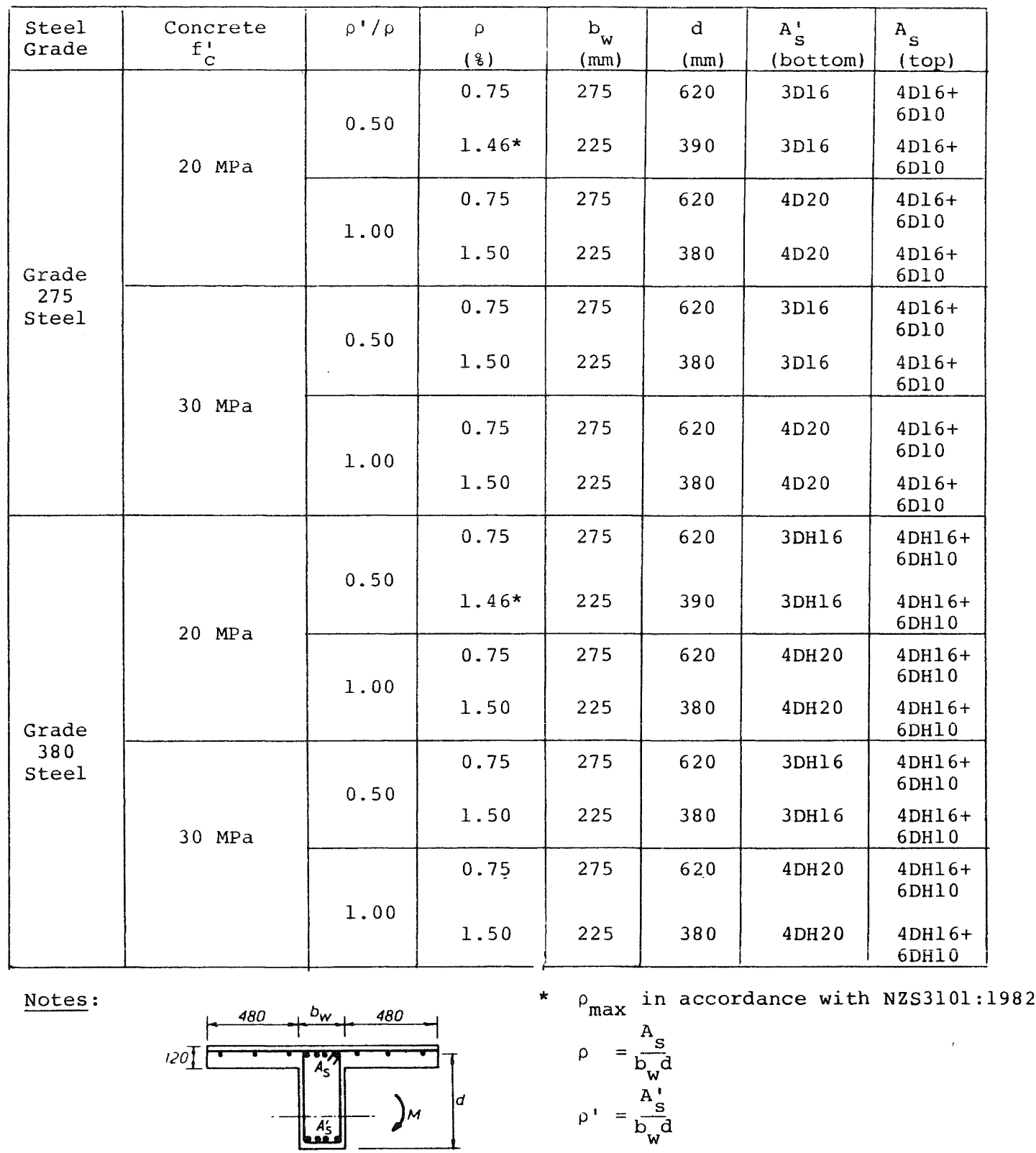


TABLE 15 : Section Properties of Rectangular Beams With Positive Moment

\begin{tabular}{|c|c|c|c|c|c|c|c|}
\hline $\begin{array}{l}\text { Steel } \\
\text { Grade }\end{array}$ & $\begin{array}{c}\text { Concrete } \\
\mathrm{C}_{\mathrm{C}}\end{array}$ & $\rho^{\prime} / \rho$ & $\begin{array}{c}\rho \\
(q)\end{array}$ & $\begin{array}{c}\mathrm{b} \\
(\mathrm{mm})\end{array}$ & $\begin{array}{c}\mathrm{d} \\
(\mathrm{mm})\end{array}$ & $\begin{array}{l}A_{S}^{\prime} \\
\text { (top) }\end{array}$ & $\begin{array}{l}\mathrm{A}_{\mathrm{S}}^{\prime} \\
\text { (bottom) }\end{array}$ \\
\hline \multirow{8}{*}{$\begin{array}{c}\text { Grade } \\
275 \\
\text { Steel }\end{array}$} & \multirow{4}{*}{$20 \mathrm{MPa}$} & \multirow[b]{2}{*}{0.50} & 0.75 & 225 & 475 & $2 \mathrm{D} 16$ & $4 \mathrm{DI} 6$ \\
\hline & & & $1.46^{*}$ & 275 & 625 & $4 D 20$ & $8 \mathrm{D} 20$ \\
\hline & & \multirow{2}{*}{1.00} & 0.75 & 225 & 475 & $4 \mathrm{DI} 6$ & $4 \mathrm{Dl} 6$ \\
\hline & & & 1.50 & 275 & 610 & $8 D 20$ & $8 D 20$ \\
\hline & \multirow{4}{*}{$30 \mathrm{MPa}$} & \multirow{2}{*}{0.50} & 0.75 & 225 & 475 & $2 \mathrm{Dl} 6$ & $4 D 16$ \\
\hline & & & 1.50 & 275 & 610 & $4 \mathrm{D} 20$ & $8 \mathrm{D} 20$ \\
\hline & & \multirow{2}{*}{1.00} & 0.75 & 225 & 475 & $4 D 16$ & $4 D 16$ \\
\hline & & & 1.50 & 275 & 610 & $8 D 20$ & $8 D 20$ \\
\hline \multirow{8}{*}{$\begin{array}{c}\text { Grade } \\
380 \\
\text { Steel } \\
\end{array}$} & \multirow{4}{*}{$20 \mathrm{MPa}$} & \multirow{2}{*}{0.50} & 0.75 & 225 & 475 & $2 \mathrm{DH} 16$ & $4 \mathrm{DH} 16$ \\
\hline & & & $1.46^{*}$ & 275 & 625 & $4 \mathrm{DH} 20$ & $8 \mathrm{DH} 20$ \\
\hline & & \multirow{2}{*}{1.00} & 0.75 & 225 & 475 & $4 \mathrm{DH} 16$ & $4 \mathrm{DHI} 6$ \\
\hline & & & 1.50 & 275 & 610 & $8 \mathrm{DH} 20$ & $8 \mathrm{DH} 20$ \\
\hline & \multirow{4}{*}{$30 \mathrm{MPa}$} & \multirow{2}{*}{0.50} & 0.75 & 225 & 475 & $2 \mathrm{DH} 16$ & $4 \mathrm{DH} 16$ \\
\hline & & & 1.50 & 275 & 610 & $4 \mathrm{DH} 20$ & $8 \mathrm{DH} 20$ \\
\hline & & \multirow{2}{*}{1.00} & 0.75 & 225 & 475 & $4 \mathrm{DHI} 6$ & $4 \mathrm{DH} 16$ \\
\hline & & & 1.50 & 275 & 610 & $8 \mathrm{DH} 20$ & $8 \mathrm{DH} 20$ \\
\hline \multirow{2}{*}{\multicolumn{3}{|c|}{ Notes: }} & & $\rho_{\max }$ & \multirow{2}{*}{\multicolumn{2}{|c|}{ in accordance with }} & \multirow[t]{2}{*}{ NZS $3101: 1982$} \\
\hline & & & $M$ & $\begin{array}{l}\rho= \\
\rho^{\prime}=\end{array}$ & & & \\
\hline
\end{tabular}

TABLE 16 : Section Properties of Square Columns

\begin{tabular}{|c|c|c|c|c|c|c|}
\hline $\begin{array}{l}\text { Steel } \\
\text { Grade }\end{array}$ & $\begin{array}{c}\text { Concrete } \\
f_{C}^{\prime}\end{array}$ & $\frac{P_{e}}{f_{C}^{\prime A} g}$ & $\begin{array}{l}b \text { and } h \\
(\mathrm{~mm})\end{array}$ & $\begin{array}{l}{ }_{\text {st }} \\
\text { (uniformly } \\
\text { distributed) }\end{array}$ & $\begin{array}{l}p_{t} \\
(z)\end{array}$ & $\begin{array}{l}\text { Transverse } \\
\text { Confining } \\
\text { Reinforcement }\end{array}$ \\
\hline \multirow{8}{*}{$\begin{array}{l}\text { Grade } \\
275 \\
\text { Steel }\end{array}$} & \multirow{4}{*}{$20 \mathrm{MPa}$} & \multirow[b]{2}{*}{0.3} & 600 & $12 \mathrm{D} 24$ & 1.5 & R12 - $98^{*}$ \\
\hline & & & 425 & $12 \mathrm{D} 24$ & 3.0 & $R 12-85$ \\
\hline & & \multirow{2}{*}{0.7} & 600 & 12024 & 1.5 & R12-62 \\
\hline & & & 425 & $12 \mathrm{D} 24$ & 3.0 & $R 12-85$ \\
\hline & \multirow{4}{*}{$30 \mathrm{MPa}$} & \multirow{2}{*}{0.3} & 600 & $12 D 24$ & 1.5 & RI2 - 42 \\
\hline & & & 425 & $12 \mathrm{D} 24$ & 3.0 & $R 12-85$ \\
\hline & & \multirow[b]{2}{*}{0.7} & 600 & 12 D24 & 1.5 & R12-65 \\
\hline & & & 425 & $12 \mathrm{D} 24$ & 3.0 & R12 - 61 \\
\hline \multirow{8}{*}{$\begin{array}{l}\text { Grade } \\
380 \\
\text { Steel }\end{array}$} & \multirow{4}{*}{$20 \mathrm{MPa}$} & \multirow[b]{2}{*}{0.3} & 600 & $12 \mathrm{DH} 24$ & 1.5 & $R I 2-98$ \\
\hline & & & 425 & $12 \mathrm{DH} 24$ & 3.0 & $R 12-85$ \\
\hline & & \multirow[b]{2}{*}{0.7} & 600 & $12 \mathrm{DH} 24$ & 1.5 & $\mathrm{R} 12-62$ \\
\hline & & & 425 & $12 \mathrm{DH} 24$ & 3.0 & Rl2 -85 \\
\hline & \multirow{4}{*}{$30 \mathrm{MPa}$} & \multirow[b]{2}{*}{0.3} & 600 & $12 \mathrm{DH} 24$ & 1.5 & RI2 - 65 \\
\hline & & & 425 & $12 \mathrm{DH} 24$ & 3.0 & $R 12-85$ \\
\hline & & \multirow{2}{*}{0.7} & 600 & $12 \mathrm{DH} 24$ & 1.5 & $R I 2-42$ \\
\hline & & & 425 & $12 \mathrm{DH} 24$ & 3.0 & $\mathrm{R} 12-61$ \\
\hline
\end{tabular}

Notes:

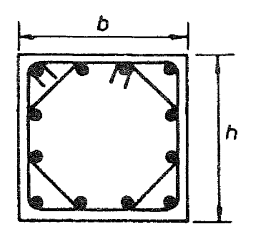

* Centre-to-centre spacing of confinement (in $\mathrm{mm}$ ) 


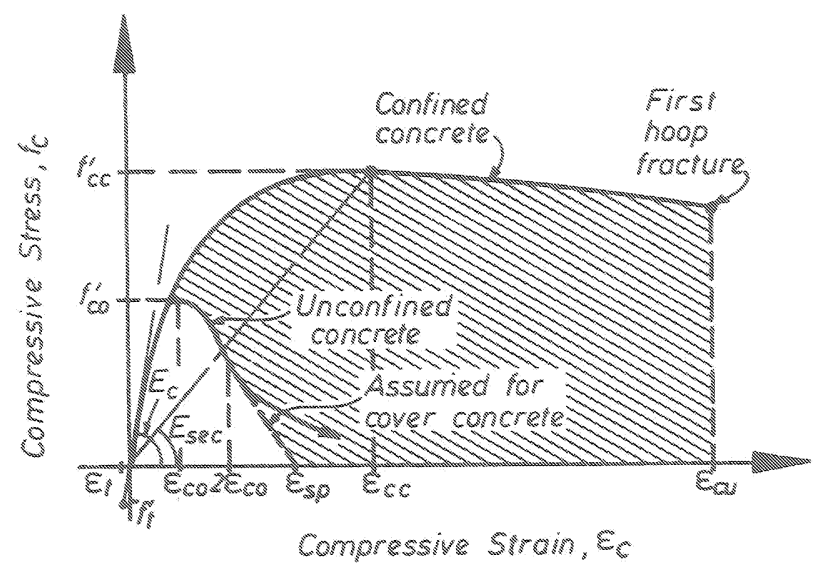

Fig. I8 Assumed Monotonic Stxess-Strain Curve for Compressed Concrete [8].

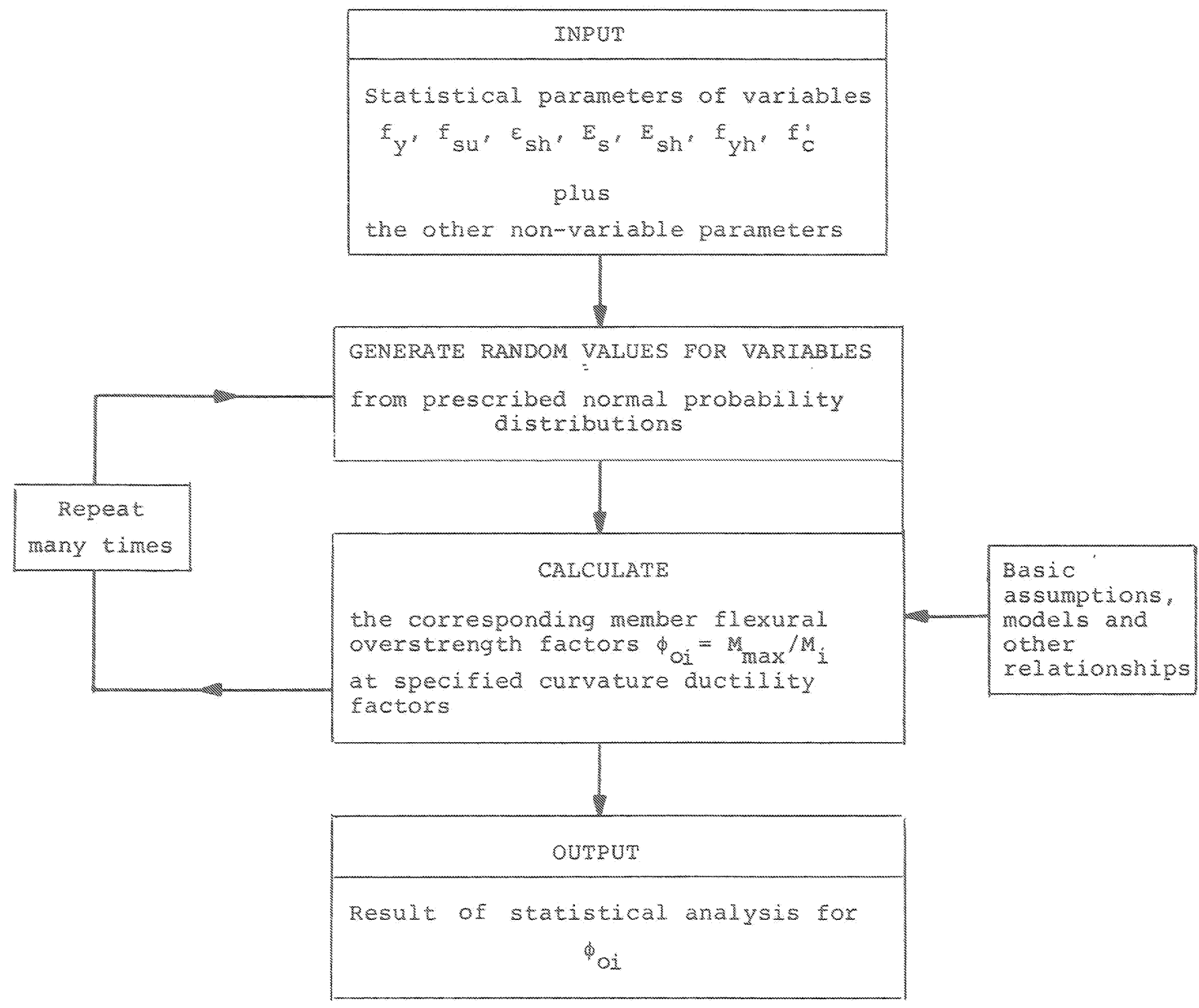

Fig. 19 Simplified Flow chart of the Computer Program using the Monte Carlo Simulation rechnique. 
The other two variable parameters are the yield strength of the transverse reinforcement $f_{y h}$ and the concrete compressive strength $\mathrm{f}_{\mathrm{C}}^{\prime}$

As non-variable data, there are several other parameters of the concrete stress-strain curve, reinforcing steel ultimate strain $\varepsilon_{\text {su }}$ and the set of section properties.

\subsubsection{Generation of Random Values for the Variables}

The Monte Carlo simulation technique used involved repetitions of momentcurvature analyses. For each momentcurvature analysis a particular set of values of the random variables are generated in accordance with the prescribed probability distributions. The principles for generating these random values with a specified normal distribution are explained in detail elsewhere $[6,21]$. Uniformly distributed random numbers are generated between 0.0 and 1.0 . Then, through appropriate transformations, the corresponding random values of the variables are generated based on the specified normal distributions within the range values of $5 \%$ lower-tail and $95 \%$ upper tail probability. since the yield strength and the ultimate strength have a relatively strong correlation with each other, the required random values for these two quantities were not generated independently. The other variable parameters were generated independently.

The Monte Carlo results are based on a finite number of samples (simulations) and cannot be "exact" unless the sample size is infinitely large. It was verified [6] that a sample size of 500 for each observation gave reasonable accuracy.

\subsubsection{Calculation of the Member Flexural overstrength Factors}

The generated values of the variables together with the other non-variable quantities were used to conduct monotonic moment-curvature analyses so as to determine the flexural overstrength factor, defined as:

$$
\phi_{O i}=\frac{M_{\max }}{M_{i}}
$$

where $M$ is the overstrength moment of resistance and $M_{i}$ is the ideal flexural strength.

The ideal flexural strength $M_{i}$ was determined using the following assumptions, which complied with section 6 of NZS 3101

[2], namely:

(a) The actual concrete compressive stress distribution is replaced by an equivalent rectangle with mean stress of $0.85 f^{\prime}$ and depth $a$, where a has the value defined by NzS 3101 [2].

(b) The extreme fibre concrete compressive strain is 0.003 .

(c) The concrete compressive strength $f_{C}^{\prime}$ is as specified.

(d) The longitudinal steel has an elastoplastic stress-strain relation. That is, strain hardening is ignored and the stress remains at the yield strength at strains greater than the yield strain.

(e) The yield strengths of the longitudinal steel are taken as the $5 \%$ lower tail values of probability. That is, $295 \mathrm{MPa}$ for Grade 275 steel and $410 \mathrm{MPa}$ for Grade 380 steel.

The overstrength moment of resistance $M$ was computed using the complete stressmaxin relationships for the steel and concrete incorporating the generated values of their variable parameters together with the values of the other non-variable parameters. After computing the ideal flexural strength, $M_{j}$, the computer program proceeds in the following steps in order to calculate the overstrength moment $M$ then the flexural overstrength factor $\phi_{o i}$.

First, the concrete section is divided into a number of discrete laminae (strips), parallel to the neutral axis of the section. Each lamina contains areas of cover and core concrete. Similarly, the longitudinal reinforcing steel is considered in a discrete number of layers parallel to the neutral axis, where each layer contains a known area of reinforcing steel. The analysis then proceeds by increasing the extreme fibre concrete compressive strain of the section gradually, in small increments. For each value of the extreme fibre concrete compressive strain the neutral axis depth is found using the bisection iteration technique. That is, the neutral axis depth is adjusted until the internal forces in the concrete and the steel, corresponding to the neutral axis depth and extreme fibre strain (see Fig. 20), are in equilibrium with the external axial load in the case of a column or sum to zero in the case of a beam. When the correct neutral axis is found the moment of resistance $M$ corresponding to that extreme fibre strain is found from the internal forces in the section. Then the ratio of $M / M_{i}$ is computed.

At each increment the curvature ductility factor $\phi / \phi_{y}$ is also determined, in which $\phi$ is the curvature corresponding to the particular extreme fibre strain and $\phi_{y}$ is the yield curvature defined as

$$
\phi_{Y}=\frac{M_{i}^{\prime}}{M_{Y}} \phi_{Y}^{\prime}
$$

where $M$ is the moment of resistance when yield is first reached in the longitudinal reinforcing steel, $\phi^{\prime}$ is the curvature corresponding to $M, Y$ and $M$ : is calculated using assumptions hentioned before for the ideal flexural strength, except that it is based on the actual concrete compressive strength and the actual steel yield strength for that analysis instead of the specified values. Fig. 21 demonstrates how $\phi$ is obtained. This definition for $\phi_{y}$ has been commonly used in New Zealand. 


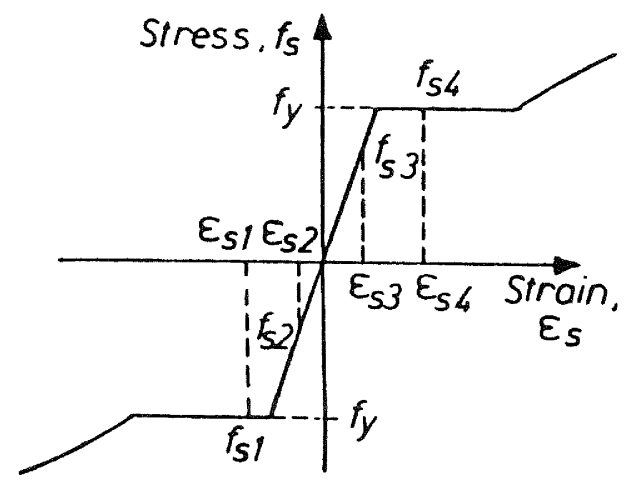

(a) Stress-Strain Relation for Steel

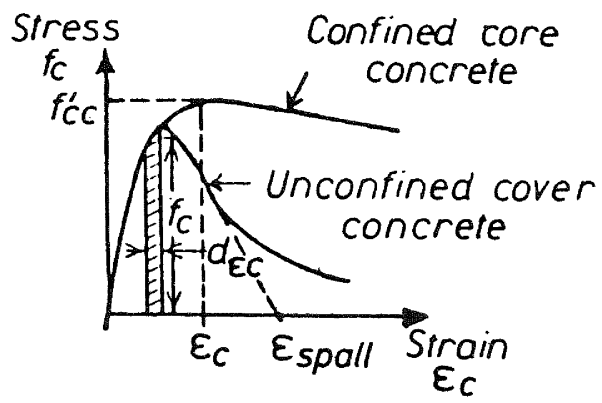

(b) Stress-Strain Relation for Concrete

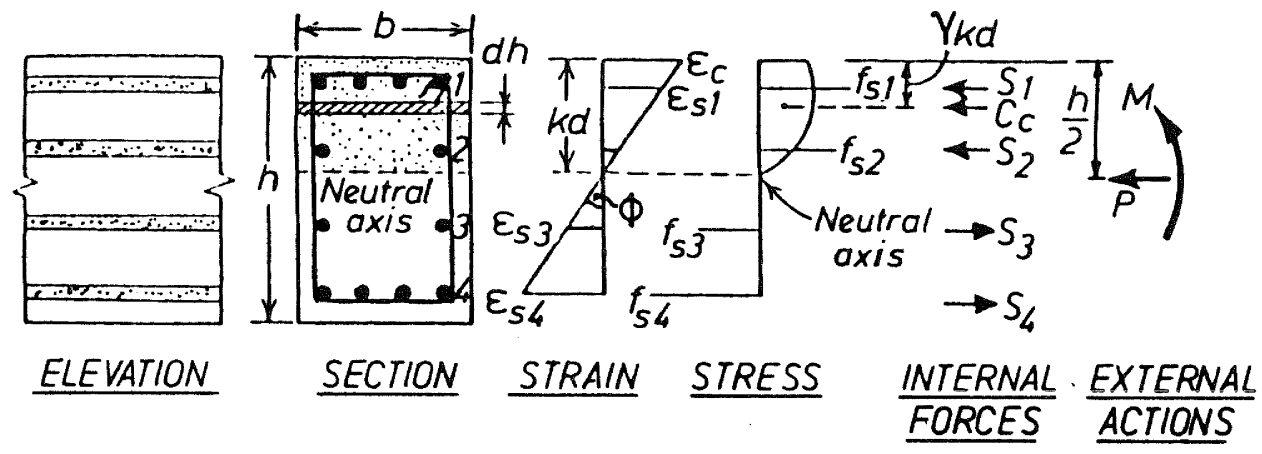

(c) Section with Strain, Stress and Force Distributions

Fig. 20 Theoretical Moment-Curvature Analysis.

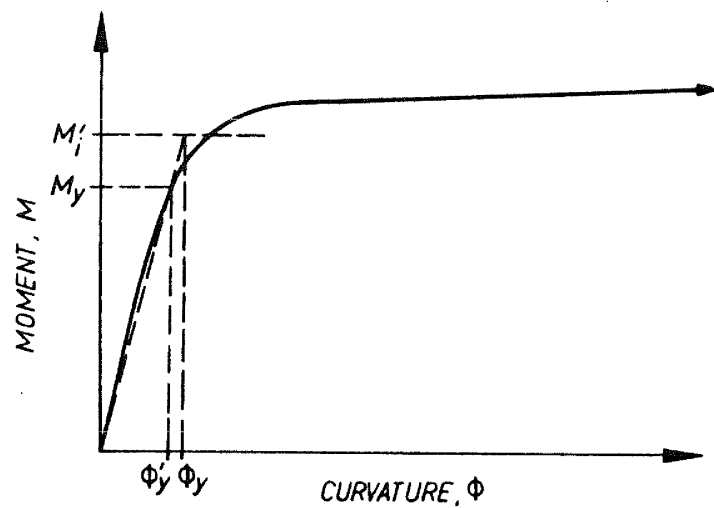

Fig. 21 Definition of Yield Curvature

The ratios $M / M_{i}$ and $\phi / \phi$ are found for increasing extreme fibre strain increments until one of the following limits is reached:

(a) The moment $M$ obtained from the last strain increment has reduced to less than 0.8M?. That is, it is considered that a reduction to less than $0.8 \mathrm{M}$ : is unacceptable and can be regarded as failure.

(b) The curvature ductility factor $\phi / \phi$ has reached 20.0. That is, it is $Y$ considered that a curvature ductility demand of 20 is a reasonable upper limit for the plastic hinge regions of a ductile frame during a severe earthquake.

(c) The maximum strain in the longitudinal steel exceeds its ultimate strain, $\varepsilon_{\mathrm{s}}>\varepsilon_{\mathrm{su}}$.

There was no limitation on the concrete compressive strain imposed since previous tests and analysis have shown that the above criteria are adequate $[8,20]$. Generally the maximum value of $M / M_{j}$ occurs at $\phi / \phi_{Y}=20$. The value of $M / M_{i}$ at $\phi / \phi_{Y}=$ 10 was $Y$ also evaluated. 


\section{5 .5 Results}

For each of the 64 combinations of variables in Tables 13, 14, 15 and 16 there were 500 repetitions of moment-curvature analyses. Hence statistical methods may be applied to 500 values of the flexural overstrength factor obtained for each of the 64 combinations of section variables in order to assess the likely flexural overstrength factors for the members. In determining the flexural overstrength factor, $M$ in Eq. 17 was taken as the maximum value of $M$ calculated up to the level of curvature ductility factor $\phi / \phi_{Y}$ considered.

The computed means of the flexural overstrength factors $\phi$ and their related coefficient of variation are listed in Tables 17, 18, 19 and 20. The KS test was applied [6] and it was verified that the values of $\left|D_{\max }\right|$ did not exceed the critical value of $D_{n}^{\alpha}$, at least at significance level $\alpha=10^{n}$. Based on this finding the normal distribution was acceptable and therefore the $95 \%$ uppertail overstrength values, also listed in Tables 17, 18, 19 and 20, were calculated using that probability model.

\section{DISCUSSION OF OVERSTRENGTH FACTORS}

\subsection{Beam Flexural Overstrength Factors}

From Tables 17, 18 and 19, it can be seen that the beam sections containing Grade 380 steel as longitudinal reinforcement have much higher overstrength factors, at both $\phi / \phi=10.0$ and at $\phi / \phi=20.0$ than the beams containing Grade 275 steel as longitudinal reinforcement. The large increase in flexural strength of the members reinforced by Grade 380 steel at high curvatures is caused mainly by the strain hardening of that steel which occurs soon after yielding. In the case of Grade 275 steel, which has longer yield plateau than Grade 380 steel, the strain hardening does not occur so early. At a curvature ductility factor of $\phi / \phi_{Y}=10.0$, the tensile strain present in Grade $\mathrm{Y}_{275}$ longitudinal steel in the beam models is generally still in the yield plateau (that is, at less than the strain hardening strain $\varepsilon_{s h}$ ), whereas the tensile strain present in Grade 380 longitudinal steel is generally greater than $\varepsilon_{\text {sh }}$, meaning that strain hardening has 8ccurred in that steel.

Tables 17,18 and 19 show that the stress-strain properties of the longitudinal reinforcing steel and the level of curvature ductility factor have the most important influence on the flexural overstrength factor for beams. In general, variations in the longitudinal steel content, concrete compressive strength, confinement from transverse reinforcement, and section shape within the normal design ranges, have much less significant effects on the flexural overstrength factors for beams.

The currently used flexural overstrength factors for beams in New Zealand are $\phi=1.25$ for Grade 275 steel and $\phi=1.40^{\circ}$ for Grade 380 steel. These currently used values were based on the more limited data on reinforcing steel properties available at the time of the formulation of NZS 3101 [3]. Table 21 shows average values of $\left(\phi_{0 i}\right) \mathrm{m}$ and $\left(\phi_{0 i}\right) .95$ obtained in this study, whlch are

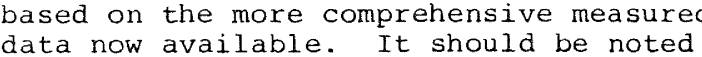
data now available. It should be noted flexural overstrength factors $\phi$ and that $\left(\phi_{\mathrm{Oi}}\right)^{\prime} .95$ is based on the mean of the 958 upper tail probability values. Also, when calculating the overstrength factors $\phi$ in this study, the $5:$ lower tail probability value of steel yield strengths was used to compute the ideal flexural strength, namely $f=295 \mathrm{MPa}$ and $\mathrm{f}_{\mathrm{f}}=410 \mathrm{MPa}$, instead of the specified minimum yield strengths, namely $275 \mathrm{MPa}$ and $380 \mathrm{MPa}$, for Grade 275 and Grade 380 steel, respectively. The curvature ductility factors $\phi / \phi=10$ and 20 are considered to be reasonable lower and upper limit demands for the plastic hinge regions of ductile reinforced concrete frames responding with a beam sidesway mechanism during a severe earthquake [4].

\subsection{Column Flexural Overstrength Factors}

From the results tabulated in Table 20 it is apparent that the variable which has the major effect on the flexural overstrength factors of columns is the level of axial load. This finding agrees with the results of previous investigations [20]. It is also detected that there are no significant differences between the column flexural overstrength factors at $\phi / \phi_{\mathrm{y}}=10$ and 20 for the columns considered in this study. The columns contained the amount of confining reinforcement recommended by N2S 3101 [3] for the potential plastic hinge regions of columns which are not protected from yielding by capacity design.

The average values of $(\phi, i)$ and $(\phi))^{\prime}$ for the two levels of axial load investigated are shown in Table 22. It is of interest to compare these results with the column flexural overstrength values obtained from the following empirical formulae proposed by Ang et al [20]:

When $\frac{P_{e}}{{f_{C}^{\prime A}}_{C}^{\prime}}<0.1, \phi_{O i}=1.30$

When $\frac{\mathrm{P}_{\mathrm{e}}}{\mathrm{E}_{\mathrm{C}}^{\mathrm{A}} \mathrm{A}} \geqq 0.1, \phi_{\mathrm{Oi}}=1.30$

$$
+2.70\left(\frac{P_{e}}{f_{C}^{\prime A}}-0.1\right)^{2}
$$

Eq. 19 gives the upper limit of $\phi$ values observed from the experimental restits of more than 33 reinforced concrete columns tested at the University of Canterbury [20]. The mean experimental values of $\phi$ were observed to be $15 \%$ lower than the ofpper limit values given by Eq. 19. The column flexural overstrength values obtained using Eq. 19 for $\mathrm{P} / \mathrm{f}^{\prime} \mathrm{A}=0.3$ and 0.7 are 1.41 and 2.27 , respectively. It is evident that Eq. 19 gives reasonable agreement with the $\left(\phi_{\text {oi }}\right) .95$ values shown in Table 22. 
TABLE 17 : T-Beam Flexural Overstrength Factors for Positive Moment at $\phi / \phi_{\mathrm{y}}=10.0$ and $\phi / \phi_{\mathrm{y}}=20.0$

\begin{tabular}{|c|c|c|c|c|c|c|c|c|c|c|c|}
\hline \multirow{3}{*}{$\begin{array}{l}\text { Steel } \\
\text { Grade }\end{array}$} & \multirow{3}{*}{$\begin{array}{c}\text { Concrete } \\
\mathrm{f}_{\mathrm{C}}^{\prime}\end{array}$} & \multirow[t]{3}{*}{$\rho^{\prime} / \rho$} & \multirow{3}{*}{$\begin{array}{c}\rho \\
\left(\frac{\partial}{\partial}\right)\end{array}$} & \multicolumn{8}{|c|}{ Confinement R10 $-6 d_{b}$ or $d / 4$} \\
\hline & & & & \multicolumn{4}{|c|}{$\phi / \phi_{y}=10.0$} & \multicolumn{4}{|c|}{$\phi / \phi_{y}=20.0$} \\
\hline & & & & $\left(\phi_{\mathrm{Oi}}\right)^{\prime} \mathrm{m}$ & $\operatorname{Cov}(8)$ & (\$oi'.95 & $\left|D_{\max }\right|$ & $\left(\phi_{\mathrm{oi}}{ }^{\prime} \mathrm{m}\right.$ & $\operatorname{Cov}(8)$ & $\left(\phi_{0 i}\right) .95$ & $\left|D_{\max }\right|$ \\
\hline \multirow{8}{*}{$\begin{array}{l}\text { Grade } \\
275 \\
\text { steel }\end{array}$} & \multirow{4}{*}{$20 \mathrm{MPa}$} & \multirow{2}{*}{0.50} & 0.75 & 1.095 & 4.51 & 1.176 & 0.0601 & 1.289 & 5.51 & 1.406 & 0.0366 \\
\hline & & & 1.46 & 1.106 & 4.30 & 1.184 & 0.0416 & 1.304 & 5.41 & 1.420 & 0.0319 \\
\hline & & \multirow{2}{*}{1.00} & 0.75 & 1.080 & 4.57 & 1.161 & 0.0649 & 1.287 & 5.48 & 1.403 & 0.0386 \\
\hline & & & 1.50 & 1.108 & 4.43 & 1.189 & 0.0442 & 1.298 & 5.12 & 1.407 & 0.0396 \\
\hline & \multirow{4}{*}{$30 \mathrm{MPa}$} & 0.50 & 0.75 & 1.085 & 4.62 & 1.167 & 0.0485 & 1.281 & 5.51 & 1.397 & 0.0455 \\
\hline & & & 1.50 & 1.090 & 4.31 & 1.167 & 0.0383 & 1.293 & 5.22 & 1.404 & 0.0247 \\
\hline & & 100 & 0.75 & 1.058 & 4.45 & 1.135 & 0.0363 & 1.263 & 5.38 & 1.375 & 0.0219 \\
\hline & & .00 & 1.50 & 1.097 & 4.51 & 1.178 & 0.0606 & 1.302 & 5.11 & 1.411 & 0.0464 \\
\hline \multirow{8}{*}{$\begin{array}{c}\text { Grade } \\
380 \\
\text { Steel }\end{array}$} & \multirow{4}{*}{$20 \mathrm{MPa}$} & \multirow{2}{*}{0.50} & 0.75 & 1.398 & 5.81 & 1.532 & 0.0422 & 1.608 & 5.23 & 1.746 & 0.0468 \\
\hline & & & 1.46 & 1.397 & 5.83 & 1.531 & 0.0509 & 1.591 & 5.09 & 1.724 & 0.0529 \\
\hline & & \multirow{2}{*}{1.00} & & 1.383 & & & 0.0380 & 1.600 & & & 0.0413 \\
\hline & & & 1.50 & 1.397 & 5.60 & 1.526 & 0.0378 & 1.577 & 4.81 & 1.702 & 0.0505 \\
\hline & \multirow{4}{*}{$30 \mathrm{MPa}$} & 0.50 & 0.75 & 1.384 & 6.08 & 1.522 & 0.0260 & 1.599 & 5.50 & 1.744 & 0.0416 \\
\hline & & & 1.50 & 1.395 & 6.02 & 1.533 & 0.0437 & 1.594 & 5.18 & 1.730 & 0.0487 \\
\hline & & & 0.75 & 1.368 & 6.01 & 1.503 & 0.0554 & 1.593 & 5.36 & 1.733 & 0.0579 \\
\hline & & (2) & 1.50 & 1.398 & 5.77 & 1.531 & 0.0350 & 1.573 & 4.72 & 1.695 & 0.0420 \\
\hline \multirow{3}{*}{$\begin{array}{l}\text { Steel } \\
\text { Grade }\end{array}$} & \multirow{3}{*}{$\begin{array}{c}\text { Concrete } \\
f_{c}^{\prime}\end{array}$} & \multirow{3}{*}{$\rho / \rho$} & \multirow{3}{*}{$\begin{array}{c}\rho \\
(o)\end{array}$} & \multicolumn{8}{|c|}{ Confinement R12-50 mm } \\
\hline & & & & \multicolumn{4}{|c|}{$\phi / \phi_{y}=10.0$} & \multicolumn{4}{|c|}{$\phi / \phi_{y}=20.0$} \\
\hline & & & & $\left(\phi_{\mathrm{Oi}}\right)_{\mathrm{m}}$ & $\operatorname{Cov}(8)$ & $\left(\phi_{0 i}\right) .95$ & $\left|D_{\max }\right|$ & $\left(\phi_{o i}\right)^{\prime}$ & $\operatorname{cov}\left(\frac{8}{8}\right)$ & $\mid\left(\phi \circ i^{\prime} .95\right.$ & ||$D_{\max } \mid$ \\
\hline & & & 0.75 & 1.094 & 4.22 & 1.170 & 0.0430 & 1.287 & 5.43 & 1.402 & 0.0361 \\
\hline & $20 \mathrm{MPa}$ & 0.30 & 1.46 & 1.108 & 4.55 & 1.191 & 0.0418 & 1.305 & 5.36 & 1.420 & 0.0386 \\
\hline & & & 0.75 & 1.079 & 4.27 & 1.155 & 0.0494 & 1.284 & 5.45 & 1.399 & 0.0207 \\
\hline & & 1.00 & 1.50 & 1.112 & 4.46 & 1.194 & 0.0528 & 1.307 & 5.23 & 1.419 & 0.0389 \\
\hline $\begin{array}{c}275 \\
\text { steer }\end{array}$ & & 0.50 & 0.75 & 1.085 & 4.55 & 1.166 & 0.0439 & 1.281 & 5.70 & 1.401 & 0.0255 \\
\hline & $30 \mathrm{MPa}$ & & 1.50 & 1.085 & 4.44 & 1.163 & 0.0535 & 1.290 & 5.22 & 1.401 & 0.0266 \\
\hline & & & 0.75 & 1.061 & 4.52 & 1.140 & 0.0463 & 1.265 & 5.40 & 1.377 & 0.0188 \\
\hline & & .00 & 1.50 & 1.096 & 4.44 & 1.175 & 0.0461 & 1.301 & 5.26 & 1.413 & 0.0279 \\
\hline & & & 0.75 & 1.391 & 6.17 & 1.532 & 0.0412 & 1.606 & 5.23 & 1.744 & 0.0425 \\
\hline & $20 \mathrm{MPa}$ & & 1.46 & 1.391 & 5.92 & 1.526 & 0.0372 & 1.582 & 5.12 & 1.715 & 0.0579 \\
\hline & & & 0.75 & 1.384 & 6.05 & 1.522 & 0.0362 & 1.599 & 5.38 & 1.740 & 0.0434 \\
\hline & & & 1.50 & 1.394 & 5.46 & 1.519 & 0.0373 & 1.568 & 4.85 & 1.693 & 0.0502 \\
\hline $\begin{array}{c}380 \\
\text { Steel }\end{array}$ & & & 0.75 & 1.380 & 5.91 & 1.514 & 0.0376 & 1.593 & 5.31 & 1.732 & 0.0449 \\
\hline & $30 \mathrm{MPa}$ & 100 & 1.50 & 1.401 & 5.84 & 1.535 & 0.0458 & 1.602 & 4.97 & 1.733 & 0.0534 \\
\hline & & & 0.75 & 1.363 & 5.94 & 1.496 & 0.0406 & 1.591 & 5.37 & 1.731 & 0.0646 \\
\hline & & & 1.50 & 1.393 & 5.96 & 1.530 & 0.0438 & 1.563 & 4.95 & L. 690 & 0.0507 \\
\hline
\end{tabular}

Notes: - Sample size $n=500$

- Critical value $D_{n}^{\alpha}$, at $\alpha=18: 0.0729$ 
TABLE 18 : T-Beam Flexural Overstrength Factors for Negative Moment at $\phi / \phi_{y}=10.0$ and $\phi / \phi_{y}=20.0$

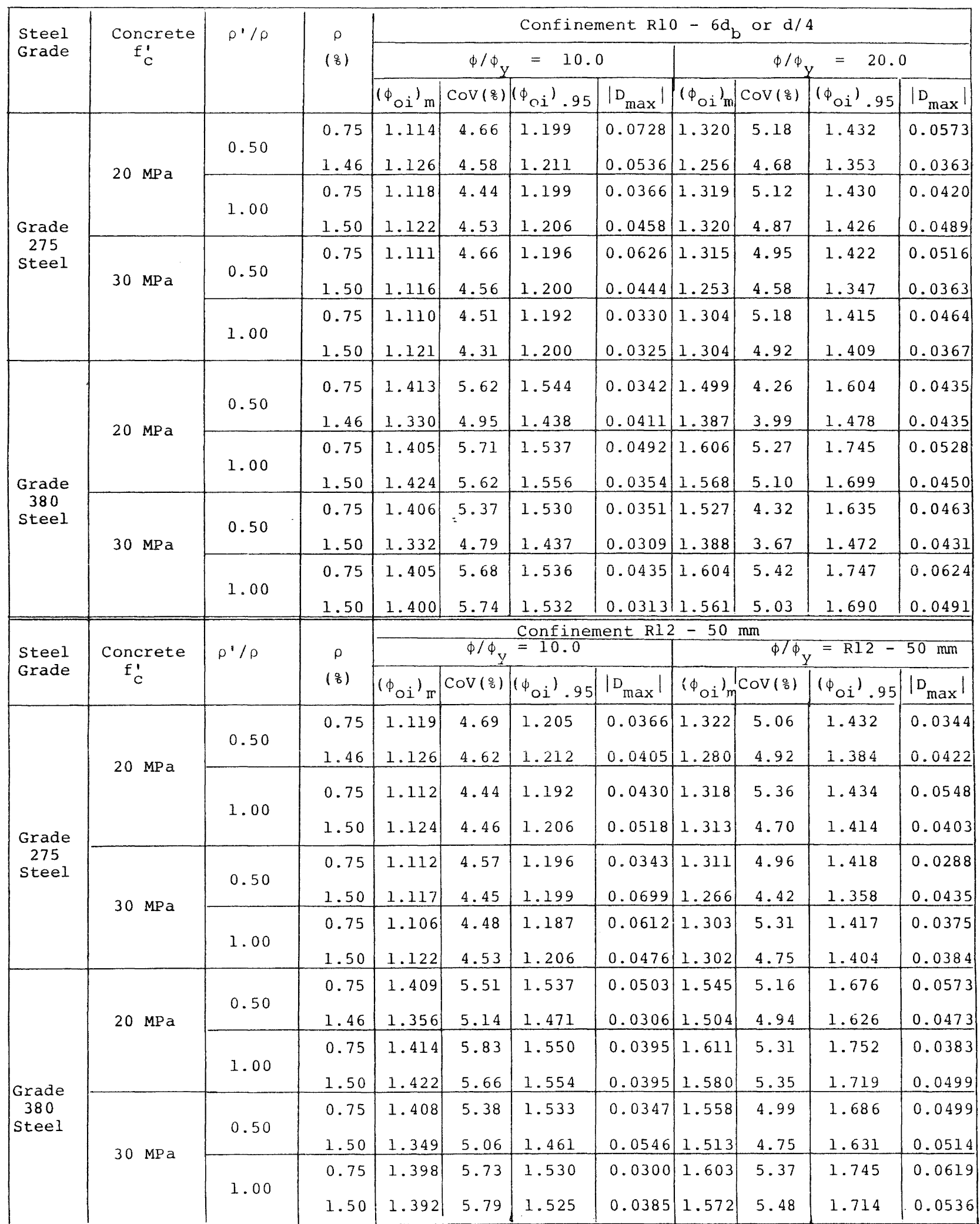

Notes: - Sample size $n=500$

- Critical value $D_{n}^{\alpha}$, at $\alpha=18: 0.0729$ 
$\frac{\text { TABLE } 19: \text { Rectangular Beam Flexural Overstrength Factors at } \phi / \phi}{\phi_{\mathrm{Y}} / \phi_{\mathrm{Y}}=20.0}$

\begin{tabular}{|c|c|c|c|c|c|c|c|c|c|c|c|}
\hline \multirow{3}{*}{$\begin{array}{l}\text { Steel } \\
\text { Grade }\end{array}$} & \multirow{3}{*}{$\begin{array}{c}\text { Concrete } \\
f_{C}^{\prime}\end{array}$} & \multirow[t]{3}{*}{$\rho^{\prime} / \rho$} & \multirow{3}{*}{$\begin{array}{c}p \\
(q)\end{array}$} & \multicolumn{8}{|c|}{ Confinement Rlo $-6 d_{b}$ or $d / 4$} \\
\hline & & & & \multicolumn{4}{|c|}{$\phi / \phi_{y}=10.0$} & \multicolumn{4}{|c|}{$\phi / \phi_{Y}=20.0$} \\
\hline & & & & $\left(\phi_{a i}\right)_{m}$ & $\operatorname{Cov}\left(\frac{8}{8}\right)$ & $\left(\phi_{0 i}\right)^{.95}$ & $\left|D_{\max }\right|$ & $\left(\phi_{O i}\right)_{m}$ & $\operatorname{Cov}(8)$ & $\left(\phi_{O i}\right) .95$ & $\left|D_{\max }\right|$ \\
\hline \multirow{8}{*}{$\begin{array}{l}\text { Grade } \\
275 \\
\text { Steel }\end{array}$} & \multirow{4}{*}{$20 \mathrm{MPa}$} & \multirow{2}{*}{0.50} & 0.75 & 1.124 & & & 0.0714 & 1.310 & 5.04 & 1.419 & 0.0628 \\
\hline & & & 1.46 & 1.122 & 4.96 & 1.213 & 0.0452 & 1.267 & 4.47 & 1.360 & 0.0440 \\
\hline & & \multirow{2}{*}{1.00} & 0.75 & 1.123 & 4.47 & 1.206 & 0.0505 & 1.310 & 5.08 & 1.419 & \\
\hline & & & 1.50 & 1.124 & 4.32 & 1.204 & 0.0393 & 1.291 & 4.75 & 1.392 & 0.0356 \\
\hline & \multirow{4}{*}{$30 \mathrm{MPa}$} & \multirow{2}{*}{0.50} & 0.75 & 1.118 & 4.63 & 1.203 & 0.0648 & 1.299 & 4.83 & 1.402 & \\
\hline & & & 1.50 & 1.119 & 4.86 & 1.208 & 0.0312 & 1.277 & 4.36 & 1.369 & 0.0376 \\
\hline & & \multirow{2}{*}{1.00} & 0.75 & 1.116 & 4.40 & 1.197 & 0.0433 & 1.296 & 4.84 & 1.399 & 0.0309 \\
\hline & & & 1.50 & 1.119 & 4.38 & 1.200 & 0.0460 & 1.278 & 4.66 & 1.376 & 0.0443 \\
\hline \multirow{8}{*}{$\begin{array}{l}\text { Grade } \\
380 \\
\text { Steel }\end{array}$} & \multirow{4}{*}{$20 \mathrm{MPa}$} & \multirow{2}{*}{0.50} & 0.75 & 1.405 & 5.28 & 1.527 & 0.0466 & 1.509 & 4.57 & 1.622 & 0.0537 \\
\hline & & & 1.46 & 1.325 & 4.63 & 1.426 & 0.0412 & 1.345 & 3.69 & 1.427 & 0.0503 \\
\hline & & \multirow{2}{*}{1.00} & 0.75 & 1.409 & 5.59 & 1.539 & 0.0494 & 1.588 & 5.37 & 1.728 & 0.0479 \\
\hline & & & 1.50 & 1.403 & 5.35 & 1.526 & 0.0575 & 1.572 & 5.06 & 1.703 & 0.0479 \\
\hline & \multirow{4}{*}{$30 \mathrm{MPa}$} & \multirow{2}{*}{0.50} & 0.75 & 1.398 & 5.12 & 1.516 & 0.0434 & 1.512 & 4.51 & 1.624 & 0.0600 \\
\hline & & & 1.50 & 1.336 & 4.39 & 1.432 & 0.0381 & 1.355 & 3.80 & 1.440 & 0.0328 \\
\hline & & \multirow[t]{2}{*}{1.00} & 0.75 & 1.389 & & 1.511 & 0.0646 & 1.553 & & 1.684 & 0.0702 \\
\hline & & & 1.50 & 1.386 & 5.17 & 1.504 & 0.0388 & 1.550 & 4.94 & 1.676 & 0.0547 \\
\hline \multirow{3}{*}{$\begin{array}{l}\text { Steel } \\
\text { Grade }\end{array}$} & \multirow{3}{*}{$\begin{array}{c}\text { Concrete } \\
f_{C}^{\prime}\end{array}$} & \multirow{3}{*}{$\rho^{\prime} / \rho$} & & & & Confineme & nt $R 12$ & $-50 \mathrm{mn}$ & & & \\
\hline & & & $\rho$ & & $\phi / \phi_{y}$ & 10.0 & & & $\phi / \phi_{y}$ & 20.0 & \\
\hline & & & $\left(\frac{8}{8}\right)$ & $\left(\phi \phi_{\mathrm{Oi}}\right)_{\mathrm{m}}$ & $\operatorname{cov}\left(\frac{\circ}{8}\right)$ & $\left(\phi_{\mathrm{Oi}}\right) .95$ & $\left|D_{\max }\right|$ & $\left(\phi_{\mathrm{Oi}}\right)_{\mathrm{m}}$ & $\operatorname{Cov}(8)$ & $\left(\phi_{\mathrm{Oi}}\right) .95$ & $\left|D_{\max }\right|$ \\
\hline & & & 0.75 & 1.126 & 4.37 & 1.207 & 0.0441 & 1.309 & 4.85 & 1.413 & 0.0420 \\
\hline & $20 \mathrm{MPa}$ & 0.50 & 1.46 & 1.124 & 5.02 & 1.217 & 0.0491 & 1.304 & 4.92 & 1.409 & 0.0477 \\
\hline & & 1) & 0.75 & I. 124 & 4.70 & 1.211 & 0.0569 & 1.312 & 5.18 & 1.424 & 0.0263 \\
\hline Grade & & 1.00 & 1.50 & 1.130 & 4.33 & 1.210 & 0.0451 & 1.307 & 4.97 & 1.414 & 0.0412 \\
\hline $\begin{array}{c}275 \\
\text { Steel }\end{array}$ & & & 0.75 & 1.118 & 4.70 & 1.204 & 0.0432 & 1.298 & 4.66 & 1.397 & 0.0413 \\
\hline & $30 \mathrm{MPa}$ & 0.50 & 1.50 & 1.122 & 5.07 & 1.216 & 0.0540 & 1.303 & 4.88 & 1.408 & 0.0518 \\
\hline & & & 0.75 & 1.117 & 4.49 & 1.199 & 0.0423 & 1.291 & 4.71 & 1.391 & 0.0399 \\
\hline & & 1.00 & 1.50 & 1.116 & 4.29 & 1.195 & 0.0555 & 1.288 & 4.84 & 1.390 & 0.0463 \\
\hline & & & 0.75 & 1.407 & 5.42 & 1.532 & 0.0453 & 1.546 & 5.01 & 1.673 & 0.0389 \\
\hline & $20 \mathrm{MP}$ & 0.30 & 1.46 & 1.378 & 5.38 & 1.500 & 0.0561 & 1.527 & 5.02 & 1.653 & 0.0494 \\
\hline & & ] & 0.75 & 1.404 & 5.56 & 1.532 & 0.0529 & 1.585 & 5.56 & 1.730 & 0.0579 \\
\hline Grade & & 1.00 & 1.50 & 1.413 & 5.49 & 1.541 & 0.0329 & 1.601 & 5.19 & 1.738 & 0.0360 \\
\hline $\begin{array}{c}380 \\
\text { Steel }\end{array}$ & & 050 & 0.75 & 1.389 & 5.33 & 1.511 & 0.0355 & 1.534 & 5.29 & 1.667 & 0.0451 \\
\hline & $30 \mathrm{MPa}$ & & 1.50 & 1.379 & 5.25 & 1.498 & 0.0409 & 1.526 & 4.78 & 1.646 & 0.0547 \\
\hline & & & 0.75 & 1.396 & 5.32 & 1.518 & 0.0414 & 1.570 & 5.35 & 1.708 & 0.0406 \\
\hline & & 1.00 & 1.50 & 1.392 & 5.62 & 1.521 & 0.0344 & 1.570 & 5.57 & 1.714 & 0.0394 \\
\hline
\end{tabular}

Notes: - Sampe size $\mathrm{n}=500$

- Critical value $D_{n}^{\alpha}$, at $\alpha=1 \%: 0.0729$

at $\alpha=10 \%: 0.0546$ 
TABLE 20 : Square Column Flexural Overstrength Factors at $\phi / \phi_{Y}=10.0$ and $\phi / \phi_{Y}=20.0$

\begin{tabular}{|c|c|c|c|c|c|c|c|c|c|c|c|}
\hline \multirow{2}{*}{$\begin{array}{l}\text { Steel } \\
\text { Grade }\end{array}$} & \multirow{2}{*}{$\begin{array}{c}\text { Concrete } \\
\mathrm{f}_{\mathrm{C}}^{\prime}\end{array}$} & \multirow{2}{*}{$\frac{\mathrm{P}_{\mathrm{e}}}{\mathrm{f}_{\mathrm{C}}^{\mathrm{A}^{\mathrm{A}} \mathrm{g}}}$} & \multirow{2}{*}{$\frac{A_{s t}}{A_{g}}$} & \multicolumn{4}{|c|}{$\phi / \phi_{y}=10.0$} & \multicolumn{4}{|c|}{$\phi / \phi_{y}=20.0$} \\
\hline & & & & $\left(\phi_{O i}\right)_{m}$ & $\operatorname{Cov}(8)$ & $\left(\phi_{0 i}\right)^{.95}$ & $\mathrm{D}_{\max }$ & $\left(\phi_{O i}\right)^{m}$ & $\operatorname{CoV}\left(\frac{8}{6}\right)$ & $\left(\phi_{O i}\right) .95$ & $\mathrm{D}_{\max }$ \\
\hline \multirow{8}{*}{$\begin{array}{c}\text { Grade } \\
275 \\
\text { steel }\end{array}$} & \multirow{4}{*}{$20 \mathrm{MPa}$} & \multirow[t]{2}{*}{0.3} & 1.5 & 1.225 & 2.96 & 1.285 & 0.0529 & 1.242 & 3.02 & 1.304 & 0.0413 \\
\hline & & & 3.0 & 1.216 & 3.05 & 1.277 & 0.0278 & 1.227 & 3.02 & 1.288 & 0.0319 \\
\hline & & \multirow{2}{*}{0.7} & 1.5 & 2.135 & 3.47 & 2.288 & 0.0395 & 2.135 & 4.35 & 2.288 & 0.0374 \\
\hline & & & 3.0 & 1.728 & 4.62 & 1.859 & 0.0392 & 1.733 & 4.43 & 1.859 & 0.0371 \\
\hline & \multirow{4}{*}{$30 \mathrm{MPa}$} & \multirow{2}{*}{0.3} & 1.5 & 1.190 & 2.39 & 1.237 & 0.0522 & 1.216 & 2.56 & 1.267 & 0.0427 \\
\hline & & & 3.0 & 1.182 & 2.88 & 1.238 & 0.0211 & 1.187 & 2.82 & 1.242 & 0.0243 \\
\hline & & \multirow{2}{*}{0.7} & 1.5 & 2.294 & 3.91 & 2.441 & 0.0560 & 2.294 & 3.91 & 2.441 & 0.0560 \\
\hline & & & 3.0 & 1.840 & 4.01 & 1.961 & 0.0431 & 1.840 & 4.01 & 1.961 & 0.0431 \\
\hline \multirow{8}{*}{$\begin{array}{c}\text { Grade } \\
380 \\
\text { Steel }\end{array}$} & \multirow{4}{*}{$20 \mathrm{MPa}$} & \multirow{2}{*}{0.3} & 1.5 & 1.337 & 3.78 & 1.420 & 0.0291 & 1.389 & 3.30 & 1.464 & 0.0325 \\
\hline & & & 3.0 & 1.345 & 4.39 & 1.442 & 0.0414 & 1.446 & 4.02 & 1.542 & 0.0409 \\
\hline & & \multirow{2}{*}{0.7} & 1.5 & 2.156 & 3.94 & 2.296 & 0.0217 & 2.182 & 3.81 & 2.319 & 0.0342 \\
\hline & & & 3.0 & 1.850 & 4.14 & 1.976 & 0.0361 & 1.923 & 3.92 & 2.047 & 0.0339 \\
\hline & \multirow{4}{*}{$30 \mathrm{MPa}$} & \multirow{2}{*}{0.3} & 1.5 & 1.307 & 3.35 & 1.379 & 0.0145 & 1.333 & 2.96 & 1.398 & 0.0220 \\
\hline & & & 3.0 & 1.296 & 3.79 & 1.377 & 0.0371 & 1.354 & 3.47 & 1.431 & 0.0329 \\
\hline & & \multirow{2}{*}{0.7} & 1.5 & 2.267 & 3.95 & 2.414 & 0.0464 & 2.268 & 3.94 & 2.415 & 0.0455 \\
\hline & & & 3.0 & 1.909 & 3.93 & 2.032 & 0.0314 & 1.914 & 3.82 & 2.034 & 0.0286 \\
\hline
\end{tabular}

TABLE 21 : Effect of Curvature Ductility Factor on Beam Flexural Overstrength Factors

\begin{tabular}{|l|c|c|c|c|}
\hline \multirow{2}{*}{$\begin{array}{l}\text { Steel } \\
\text { Grade }\end{array}$} & \multicolumn{2}{|c|}{ Average value of $\left(\phi_{\mathrm{Oi}}\right)_{\mathrm{m}}$} & \multicolumn{2}{c|}{ Average value of $\left(\phi_{\mathrm{Oi}}\right) .95$} \\
\cline { 2 - 5 } & at $\phi / \phi_{\mathrm{Y}}=10.0$ & at $\phi / \phi_{\mathrm{Y}}=20.0$ & at $\phi / \phi_{\mathrm{Y}}=10.0$ & at $\phi / \phi_{\mathrm{Y}}=20.0$ \\
\hline Grade 275 & 1.11 & 1.30 & 1.19 & 1.40 \\
\hline Grade 380 & 1.39 & 1.55 & 1.52 & 1.68 \\
\hline
\end{tabular}

TABLE 22 : Effect of Axial Load Level on Column Flexural Overstrength Factors

\begin{tabular}{|c|c|c|c|c|c|}
\hline \multirow{2}{*}{$\frac{P_{e}}{f_{c}^{\prime} A_{g}}$} & \multicolumn{2}{|c|}{$\left(\phi_{\mathrm{Oi}}\right)_{\mathrm{m}}$} & \multicolumn{2}{|c|}{$\left(\phi_{O_{i}}\right) .95$} & \multirow{2}{*}{$\begin{array}{c}\text { Based on } \\
\text { Eq. } 19\end{array}$} \\
\hline & Av. Value & $\operatorname{Cov}\left(\frac{2}{8}\right)$ & Av. Value & $\operatorname{CoV}(8)$ & \\
\hline 0.3 & 1.28 & 6.31 & 1.35 & 6.98 & 1.41 \\
\hline 0.7 & 2.03 & 10.15 & 2.16 & 10.00 & 2.27 \\
\hline
\end{tabular}

Notes: $\left(\phi_{O i}\right)_{m}=$ mean of $\phi_{O i}$

$\left(\phi_{0 i}\right)_{.95}=$ mean of 958 upper tail normal probability values of $\phi_{O i}$ 


\subsection{Effect of the Proposed Flexural overstrength Factors on Steel Usage}

It is of interest to compare the quantities of reinforcement required in ductile moment resisting reinforced concrete frames designed using the currently adopted yield strengths and overstrength factors and designed using the values suggested in this study. In this comparison it will be assumed that the curvature ductility demand at the plastic hinge regions in the beams is $\phi / \phi_{y}=15$.

\section{(a) Using Grade 275 Longitudinal Steel}

According to this study the flexural overstrength factor can be taken as approximately $\phi_{0}=1.30($ see $\mathrm{Table} 21)$, with the ideal strengths calculated using $\mathrm{f}=$ $295 \mathrm{MPa}$ for deformed longitudinal steel and $\mathrm{f}_{\mathrm{Y}}=300 \mathrm{MPa}$ for plain round transverse steel. These values can be compared with the currently used values of $\phi_{O i}=1.25$ and $f_{y}=275 \mathrm{MPa}$.

The effects of using the $\phi_{o i}$ and $f_{y}$ values proposed in this study on the $y$
quantities of longitudinal and transverse quantities of longitudinal and transverse of ductile frames designed on the basis of a strong column-weak beam concept are:

(i) The amount of longitudinal steel is reduced to approximately $(275 / 295) \times$ $100=93 \%$ of the currently calculated quantity, due to the higher proposed design yield strength.

(ii) The amount of transverse beam steel required to resist the beam shear induced by the beam overstrength moments found using capacity design is reduced to approximately

$$
\frac{1.30}{1.25} \times \frac{275}{300} \times 100=95 \%
$$

of the currently calculated quantity, where the $1.30 / 1.25$ is due to the change in $\phi$ value, and the $275 / 300$ is due to the yield strength of the shear reinforcement being taken as $300 \mathrm{MPa}$ rather than $275 \mathrm{MPa}$.

Similarly the amounts of longitudinal and transverse steel required in the columns and beam-column joint cores, found from the beam overstrength moments using capacity design are reduced to approximately 95 to $96 \%$ of the currently calculated quantities due to the reduced longitudinal beam steel and change of $\phi_{o i}$ and $f_{y}$ values.

It is evident that in this case using the $\phi$ and $f$ values proposed in this study will piead to $y_{a}$ reduction in reinforcement required.

(b) Using Grade 380 Longitudinal Steel

According to this study, approximately $\phi_{0}=1.60$ (see Table 21) with the ideal stiengths calculated using $f=410 \mathrm{MPa}$ for deformed longitudinal steel and $f=300$ MPa for plain round (Grade 275) transverse steel. These values can be compared with the currently used values of $\phi_{O i}=1.40$ and $f_{y}=380$ or $275 \mathrm{MPa}$.

The effects of using the $\phi_{o j}$ and $f_{y}$
proposed in this study are?

values proposed in this study are! is reduced to approximately $(380 / 410)$ $x 100=938$ of the currently used quantity.

(ii) The amount of transverse beam steel required to resist the beam shear induced by the beam overstrength moments found using capacity design is increased to approximately

$$
\frac{1.60}{1.40} \times \frac{275}{300} \times 100=105 \%
$$

of the currently calculated quantity.

Similarly, the amounts of longitudinal and transverse steel required in the columns and beam-column joint cores are increased to approximately 105 to 1068 of the currently calculated quantities.

It is evident that in this case using the $f$ and $\phi$ values proposed in this study will $y_{\text {lead }}$ t $8^{1}$ a reduction in the

longitudinal reinforcement required in the beams but an increase in the other reinforcement required.

\section{CONCLUSIONS AND RECOMMENDATIONS}

\subsection{Conclusions}

Conclusions from the results obtained in this study of the properties of Grade 275 and 380 reinforcing steel manufactured by Pacific Steel Ltd, Auckland, during at least the last 5 years, are as follows:

(a) The stress-strain relationships for Grace 275 and 380 reinforcing steel can be defined in terms of six variable basic parameters; namely the yield strength $\mathrm{f}_{\mathrm{y}^{\prime}}$ the ultimate strength $f$, the strain $y^{\prime}$ hardening strain $\varepsilon_{\text {, }}$, the strain at ultimate strength $\xi^{\prime}$, the modulus of elasticity $E$ and the strain hardening modulus of the steel $E_{\text {sh }}$ at $\operatorname{strain} \varepsilon_{\text {sh. }}$.

(b) The statistical study verified that the sample values of the variable parameters $f^{\prime} f_{\text {su }}, \varepsilon_{\text {sh' }}, E_{s}$ and $E_{\text {sh }}$ were normally distributed. 'S The number of sample values of $\varepsilon$ were insufficient for any statistical conclusions to be reached.

(c) The $5 \%$ lower tail normal probability value of the yield strength $f$ was $295 \mathrm{MPa}$ for Grade 275 steel deformed bars, $300 \mathrm{MPa}$ for Grade 275 steel plain bars, and $410 \mathrm{MPa}$ for Grade 330 steel deformed bars. There was no significant influence of bar diameter on the measured yield strengths.

(d) It was found that there was a strong correlation between the yield strength and the ultimate strength for a given bar. For Grade 275 steel the ultimate strength was around 1.4 times its yield strength, whereas for Grade 380 steel the ultimate strength was around 1.5 times its yield strength. 
(e) The flexural overstrength factors for beams, $\phi_{0 i}=M_{\text {max }} / M_{j}$, were found by statistical analysigi. Thex moment $M$ is the overstrength moment at a pamaxcular curvature ductility factor $\phi / \phi$ found by momentcurvature analysis incorporating the Monte Carlo simulation technique to take into account the likely variation of the steel and concrete stress-strain properties, and $M$. is the ideal flexural strength calculated using the 58 lower tail normal probability value of steel yield strength.

(f) The flexural overstrength factors $\phi_{O i}$ for beams to be used in the capacity design of earthquake resistant structures can be obtained from Tables 17,18 and 19 for specific beam cases. Alternatively, average values for $\phi$ i can be used. Based on the average valuesiof the $95 \%$ upper tail normal probability of the beam flexural overstrength factors, it was found that:

If Grade 275 steel deformed bars are used as longitudinal reinforcement:

$$
\begin{aligned}
& \phi_{\mathrm{Oi}}=1.19 \text { at } \phi / \phi_{\mathrm{Y}}=10.0 \\
& \phi_{\mathrm{O} i}=1.40 \text { at } \phi_{\mathrm{Y}}=20.0
\end{aligned}
$$

If Grade 380 steel deformed bars are used as longitudinal reinforcement:

$$
\begin{aligned}
& \phi_{O i}=1.52 \text { at } \phi / \phi_{Y}=10.0 \\
& \phi_{O i}=1.68 \text { at } \phi / \phi_{y}=20.0
\end{aligned}
$$

The curvature ductility factors $\phi / \phi_{y}$ of 10 and 20 are regarded as the lower $Y$ and upper limit of curvature demand at the plastic hinges of a ductile reinforced concrete moment resisting frame designed according to NzS 3101 .

For Grade 275 steel, the currently used flexural overstrength factor [3], namely $\phi_{0}=1.25$, falls between the above values $f 8$ the two curvature ductility factors. However, for Grade 380 steel, the currently used flexural overstrength factor [3], namely $\phi_{o i}=1.40$, is unconservative.

(g) The large beam flexural overstrength factors $\phi$ found in this study are due to two main Câses. First, the $95 \%$ upper tail yield strengths of the steel are significantly higher than the $5 \%$ lower tail values, namely $18 \%$ higher for Grade 275 steel and $26 \%$ higher for Grade 380 steel. Second, the increase in steel stress above the yield strength due to strain hardening can be significant. For Grade 275 steel where the strain hardening commences at approximately 14 times the yield strain, this effect is only significant at high curvatures. However, for Grade 380 steel where the strain hardening occurs at approximately 4 times the yield strain, this effect is much more significant even at $\phi / \phi_{y}=10.0$.

(h) For columns the average values of the 958 upper tail normal probability of the flexural overstrength factors was influenced mainly by the axial load level and showed a reasonable fit to the flexural overstrength values obtained from the empirical formula proposed as a result of previous experimental research conducted at the University of Canterbury [20].

\subsection{Recommendations}

Recommendations based on the results of this study are as follows:

(a) Use of the specified minimum yield strength of reinforcing steel in strength design may be considered to be unduly conservative, since all yield strengths of the grade of steel will be equal to or greater than that value. Use of the 58 lower tail normal probability value of steel yield strength provides a more reasonable basis for strength design than the specified minimum yield strength. This would mean using $295 \mathrm{MPa}$ and $410 \mathrm{MPa}$, rather than $275 \mathrm{MPa}$ and $380 \mathrm{MPa}$, for deformed bars from Grade 275 steel and Grade 380 steel, respectively, and $300 \mathrm{MPa}$ for plain round bars from Grade 275 steel. This will lead to less reinforcement required and hence to economies in design. The $5 \%$ lower tail value is currently used in European and British codes when defining the characteristic yield strength which is used in design.

(b) If the curvature ductility factor demands of the beam plastic hinges in a ductile moment resisting reinforced concrete framed structure, which is designed for adequate ductility to resist seismic forces in accordance with N2S 3101 [2], are not assessed, the average value of beam overstrength factors $\phi_{0 i}$ required for capacity design may be taken as:

- When Grade 275 steel is used as flexural reinforcement:

Overstrength $\cong 1.30 \times$ Ideal Strength

- When Grade 380 steel is used as flexural reinforcement:

Overstrength $\cong 1.60 \mathrm{x}$ Ideal Strength.

These values are based on the flexural capacity of the beam plastic hinges when a curvature ductility factor of approximately 15 is reached.

(c) If the above values for the beam flexural overstrength factors are used in design it is to be noted that the ideal strengths of the members (for example, the ideal shear strength provided by the transverse reinforcement), resisting the overstrength actions found by capacity design, should be calculated using the 5 \% lower tail yield strength rather than the specified minimum yield strength. It can be demonstrated that using the beam overstrength factors and yield strengths recommended in this study in design will always lead to a reduction in the longitudinal steel required at the plastic hinges in beams, and either a reduction in the steel required elsewhere in the frame if Grade 275 steel is used or a slight increase if Grade 380 steel is used.

(d) If the specified minimum yield strengths of the reinforcing steel are used as a basis for strength design, rather than the 58 lower tail yield 
strengths suggested, the above recommended beam overstrength factors should be multiplied by 1.08 , which is the ratio of the 58 lower tail yield strength to the specified minimum yield strength.

(e) If the length of the yield plateau of high strength reinforcing bar, such as Grade 380 steel currently manufactured, could be increased, it would minimize the influence of steel strain hardening on the flexural overstrength of reinforced concrete members, thus leading to a much greater acceptance of that steel for use in the design of earthquake resistant structures, which eventually may result in possible economies and less congestion of reinforcement.

\section{ACKNOWLEDGEMENTS}

The investigation described was carried out in the Department of Civil Engineering, University of Canterbury, by Takim Andriono as part of his studies for the degree of Master of Engineering, under the supervision of Professor $R$. park.

The cooperation given by Pacific Steel Ltd. of Auckland, in providing a great deal of data and valuable financial assistance, is gratefully acknowledged.

Thanks are also expressed to the University of Canterbury staff for their contributions, particularly Mrs. A. Watt for typing this paper.

\section{REFERENCES}

[1] "Code of Practice for General Structural Design and Design Loadings for Buildings, NZS 4203:1984",

Standards Association of New Zealand, $1984,100 \mathrm{pp}$.

[2] "Code of Practice for the Design of Concrete Structures, NZS 3101: Part 1, $1982 "$ " Standards Association of New Zealand, 1982, 127pp.

[3] "Commentary on the Design of Concrete Structures, NZS 3101:Part 2, 1982", Standards Association of New Zealand, $1982,156 \mathrm{pp}$.

[4] Park, R. and Paulay, T., "Reinforced Concrete Structures", John Wiley and Sons, New York, 1975, 769p.

[5] Park, R., "Constitutive Relations of Steel: Effects on Strength Considerations in Seismic Design", Proceedings of Workshop on Earthquake Resistant Reinforced Concrete Building Construction, Vol. II, University of California, Berkeley, July 1977, pp. 683-695.

[6] Andriono, T. and Park, R., "Properties of New Zealand Reinforcing Steel Used in Seismic Design", Research Report 86-9, Department of Civil Engineering, University of Canterbury, 1986, 187pp.
Bars for the Reinforcement of Concret NZS 3402P:1973", Standards Associatic of New Zealand, 1973, 16pp.

[8] Mander, J.B., Priestley, M.J.N. and Park, R., "Seismic Design of Bridge Piers", Research Report 84-2 Department of Civil Engineering, University of Canterbury, 1984, 442p plus appendices.

[9] Thompson, K.J. and Park, R., "StressStrain Model for Grade 275 Reinforcir steel with Cyclic Loading", Bulletin of New Zealand National Society for Earthquake Engineering, Vol. 11, No. 2, June 1978, pp.101-109.

[10] "Building Code Requirements for Reinforced Concrete, ACI 318-83", ACI Committee 318, American Concrete Institute, Detroit, 1983, 1llp.

[11] Mirza, S.A. and MacGregor, J.G. "Variability of Mechanical Properties of Reinforcing Bars", Journal of the Structural Division, ASCE, Vol. 105 No. ST5, May 1979, pp.921-937.

[12] Ang, A.H.S. and Tang, W.H. "Probability Concepts in Engineering Planning and Design", Vol. 1 - Basic Principles, John Wiley \& Sons, New York, 1975, 409p.

[13] Benjamin, J.R. and Cornell, C.A. "Probability, Statistics and Decision for Civil Engineers", McGraw-Hill, U.S.A., 1970, 684p.

[14] Nie, N.H. et al., "SPSS - Statistical Package for the Social Sciences". McGraw-Hill, U.S.A., 2nd edition, $1975,675 p$.

[15] Hull, C.H. and Nie, N.H., "SPSS Update 7-g, New Procedures and Facilities for Releases 7-g", McGraw-Hill, U.S.A., $1981,402 \mathrm{p}$.

[16] Fisz, M., "Probability Theory and Mathematical Statistics", 'John Wiley \& Sons, New York, 3rd edition, 1963 . 677 p plus errata.

[17] "Methods for Tensile Testing of Metals, BS18:Part 2, 1971", British Standards Institute, 1971, 28p.

[18] Kreyzig, E., "Introductory Mathematical Statistics, Principles and Methods", John Wiley \& Sons, New York, U.S.A. 1970,470 p.

[19] "Specification for Concrete Construction, NZS 3109:1980" Standards Association of New Zealand, $1980,47 \mathrm{p}$

[20] Priestley, M.J.N. and Park, R., "Strength and Ductility of Bridge Substructures", Bulletin 71, Road Research Unit, National Roads Board, Wellington, 1984, 120p. 
[21] Ang, A.H.S. and Tang, W.H., "Probability Concepts in Engineering Planning and Design", Vol. 2 Decision, Risk and Reliability, John Wiley \& Sons, New York, 1984, 562p.

\section{NOTATION}

a = depth of equivalent rectangular compressive stress block as defined by NZS 3101

$\mathrm{A}_{\mathrm{g}}=$ gross area of column section

$A_{S}$ = area of longitudinal tension reinforcement

$\mathrm{A}_{\mathrm{S}}^{\prime}=$ area of longitudinal compression reinforcement

$A_{\text {st }}=$ total area of longitudinal reinforcement

$\mathrm{b} \quad=$ width of a column and flange of $\mathrm{a}$ beam

$b_{w}=$ width of web of beam

$\mathrm{CoV}=$ coefficient of variation

$D_{\max }=$ the maximum difference between the cumulative frequency of the existing data and the assumed theoretical distribution function

$D_{n}=$ a random variable of $D_{m a x}$ whose distribution depends $\max _{\text {the }}$ sample size $\mathrm{n}$

$D_{n}^{\alpha}=$ the critical value for $D_{\text {max }}$ at a significant level $\alpha$ where the sample size is $n$

d = distance from extreme compression fibre to the centroid of the tension reinforcement

$\mathrm{E}_{\mathrm{C}} \quad=$ modulus of elasticity of concrete

$\mathrm{E}_{\mathrm{S}} \quad$ modulus of elasticity of steel

$E_{\text {sec }}=f_{C C}^{\prime} / \varepsilon_{C C}$

$\mathrm{E}_{\mathrm{Sh}}=$ strain hardening modulus for steel at $\varepsilon_{\text {sh }}$

$E_{t} \quad=$ tangent moduius of steel

$\mathrm{f}_{\mathrm{c}} \quad=$ longitudinal stress in concrete

$f_{C}^{\prime}=$ compressive cylinder strength of concrete (unconfined strength)

$f_{c c}^{\prime}=$ peak strength of confined concrete

$\mathrm{f}_{\mathrm{s}}=$ steel stress

$\mathrm{f}_{\text {su }}=$ ultimate steel strength

$f_{y}=y i e l d$ strength of longitudinal reinforcement $\mathrm{f}_{\mathrm{yh}}=\underset{\text { reinforcement }}{\text { yield strength of transverse }}$

$\mathrm{h}=$ overall depth of column or beam

$\mathrm{M} \quad$ = bending moment

$M_{i} \quad=$ ideal flexural strength calculated in accordance with section 6.3.1 of NZS 3101 when the specified material strengths are used

$M_{i} \quad$ = ideal flexural strength obtained from the same approach as for $M$ but using the actual measured material strengths rather than the specified strengths

$M_{\max }$
$M_{y}=$ moment calculated at first yield of the longitudinal reinforcement

$\mathrm{n}$ = number of sample values or sample size

$p=$ strain hardening power

$\mathrm{P}_{\mathrm{e}}=$ design axial load in compression at given eccentricity due to gravity and seismic loading acting on the member during an earthquake

$r=E_{c} /\left(E_{c}-E_{s e c}\right)$

$x=\varepsilon_{c} / \varepsilon_{C C}$

$\alpha=$ significance level

$\varepsilon_{c}=$ longitudinal concrete strain

$\varepsilon_{\mathrm{CC}}=$ longitudinal strain at maximum confined concrete stress

$\varepsilon_{\mathrm{co}}=$ longitudinal strain at maximum unconfined concrete stress

$\varepsilon_{s}=$ steel strain

$\varepsilon_{\text {sh }}=$ steel strain at the commencement of strain hardening

$\varepsilon_{\text {spall }}=$ longitudinal strain at which cover concrete is considered to have completely spalled and ceases to carry any stress

$\varepsilon_{\text {su }}=$ ultimate steel strain

$E_{y}=$ yield strain of steel

$\dot{\varepsilon}^{Y}=$ strain rate

$\rho=\mathrm{A}_{\text {ment }} / \mathrm{bd}=$ ratio of tension reinforce-

$\rho^{\prime}=A_{S}^{\prime} / b d=$ ratio of compression rềinforcement

$\rho_{t}=$ volumetric ratio of longitudinal reinforcement based on the gross section area $\mathrm{A}_{\mathrm{g}}$

$\phi=$ section curvature

$\phi_{O i}=M_{\max } / M_{i}=$ flexural overstrength factor

$\left(\phi_{\mathrm{oi}}\right)_{\mathrm{m}}=$ mean value of $\phi_{o i}$ values

$\left(\phi_{0 i}\right)^{\prime} 95$ mean value of the $95 \%$ upper tail normal probability values of $\phi_{0 i}$

$\phi_{y}=$ theoretical yield curvature

$\phi_{y}^{Y}=$ curvature calculated at first yield of the longitudinal reinforcement 